\title{
LIVING \\ PRECARIOUSLY \\ Understanding International Students' Housing Experiences in Australia
}

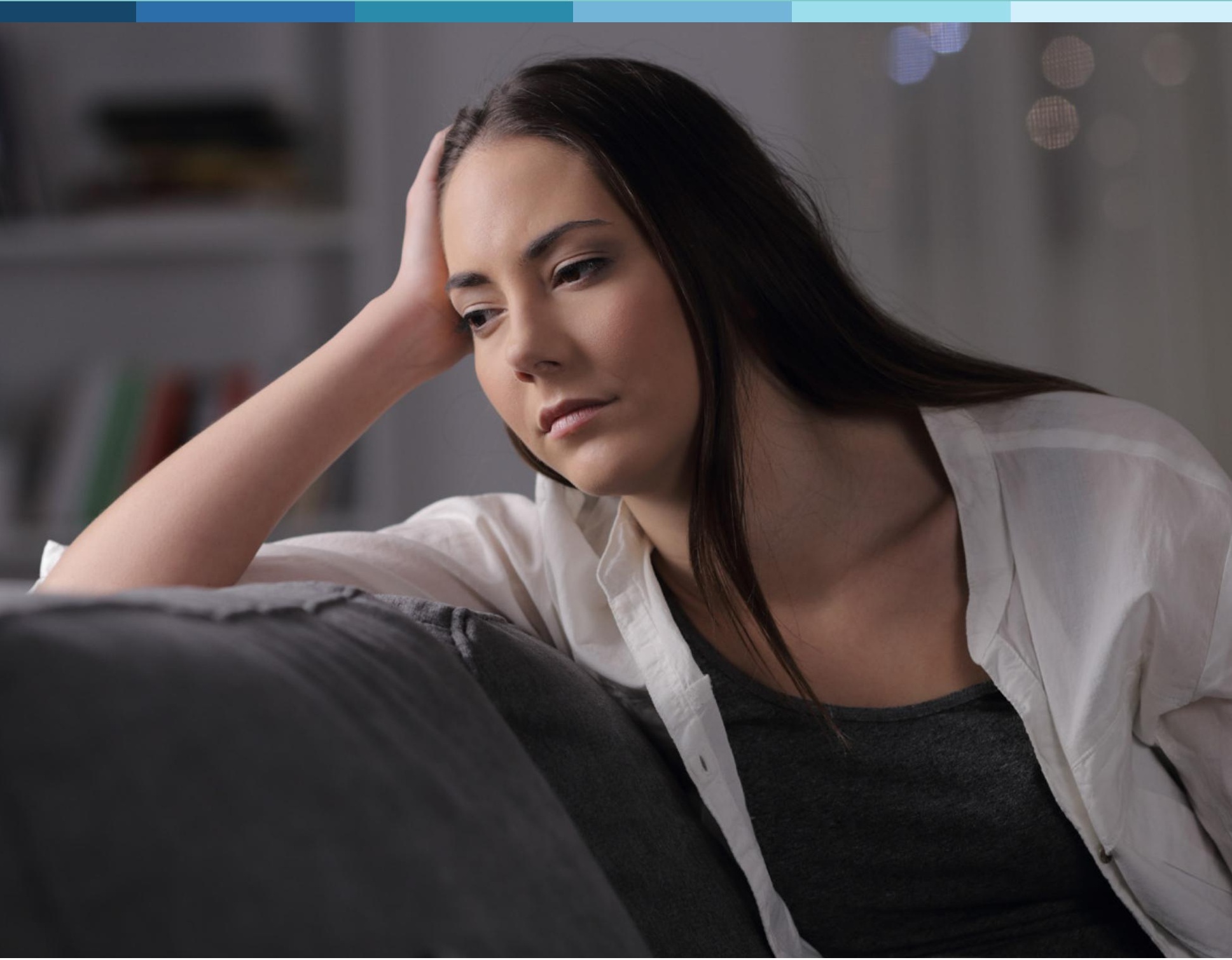

poserses
UNSW Law

产UTS 


\section{Authors}

Laurie Berg is Senior Lecturer in the Faculty of Law, University of Technology Sydney.

Bassina Farbenblum is Associate Professor in the Faculty of Law, UNSW Sydney. She is the founding director of UNSW Law's Human Rights Clinic.

Laurie and Bassina co-direct the Migrant Worker Justice Initiative (www.mwji.org), which engages in detailed empirical research in Australia and globally to catalyse improved enforcement of rights and just remedies for temporary migrants.

(c) Laurie Berg and Bassina Farbenblum 2019. All material in this report is provided under a Creative Commons Attribution-NonCommercialNoDerivatives 4.0 International (CC BY-NC-ND 4.0) licence.

Design and layout Hard Working Farmboys

Cover image istockphoto 


\section{Contents}

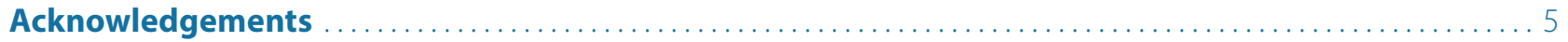

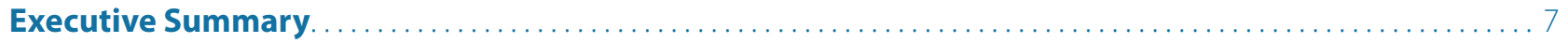

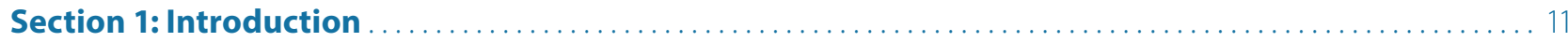

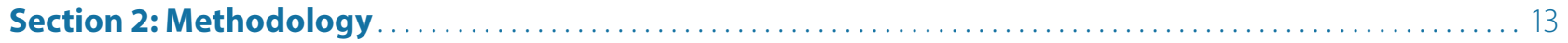

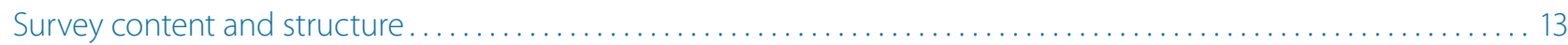

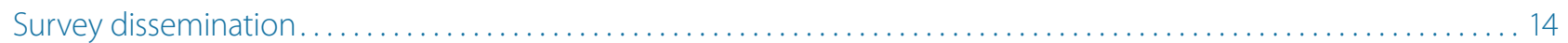

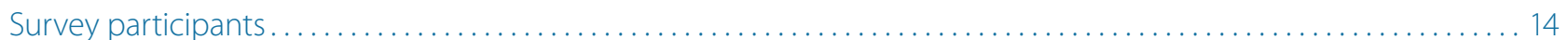

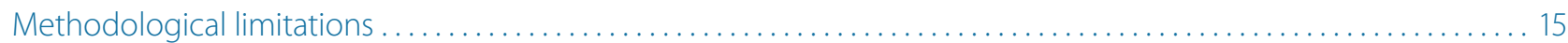

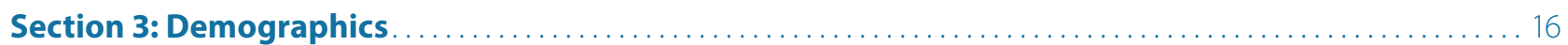

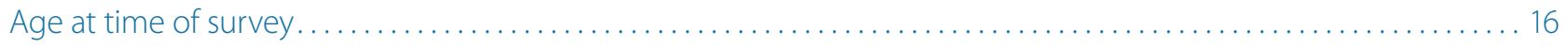

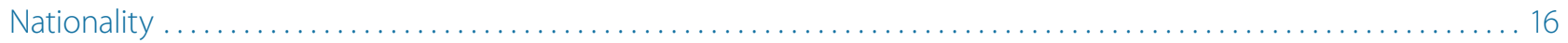

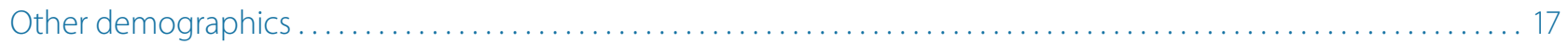

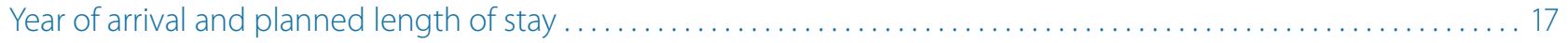

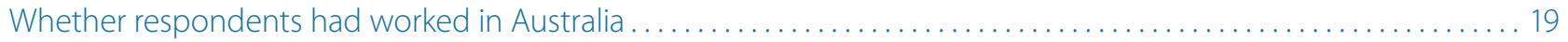

Respondents' type of first education provider and first program of study in Australia .................... 19

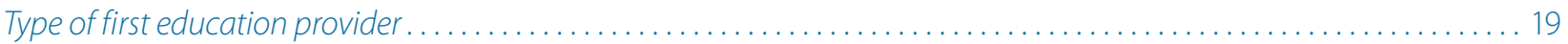

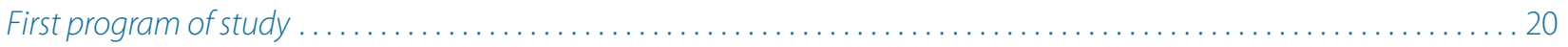

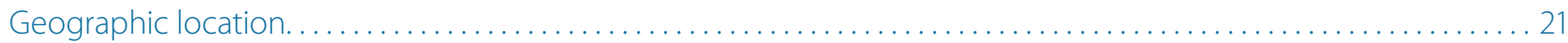

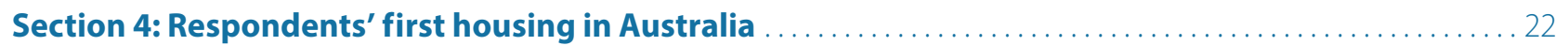

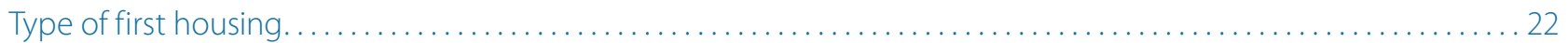

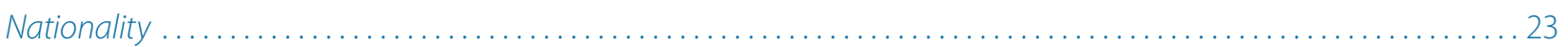

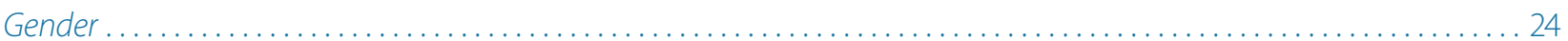

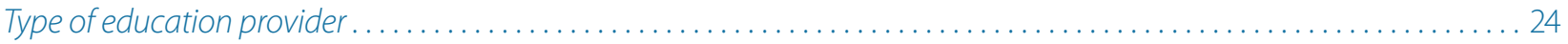

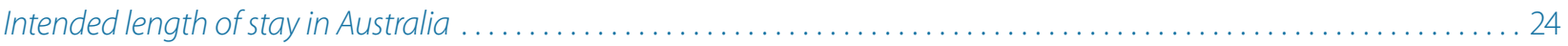

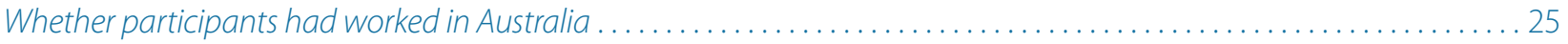

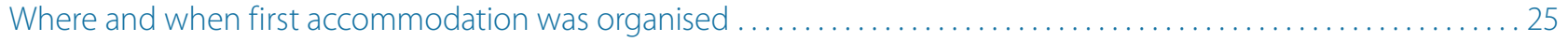

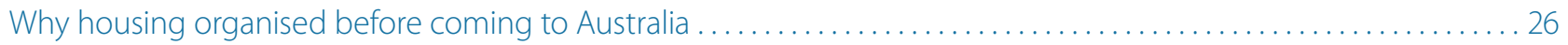

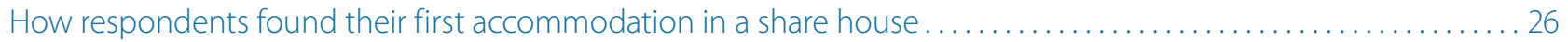

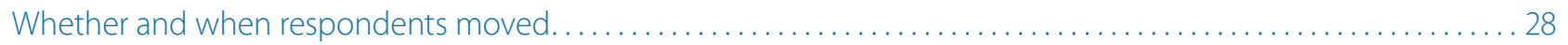

Section 5: Experiences of problems in international students' first housing in Australia . . . . . . . . . . . 29

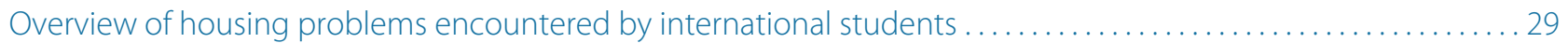

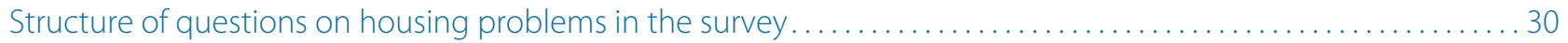

Experiences of problems for share houses compared with other types of first accommodation ..............30 
Experiences of problems in first housing found through peer-to-peer sharing websites, social media and other channels. .

Prevalence of problems in share houses organised before coming to Australia and housing organised after arrival . .

Section 6: Experiences of problems in subsequent accommodation and among different demographic cohorts

Comparing the experience of problems in first and subsequent accommodation ..................... 39

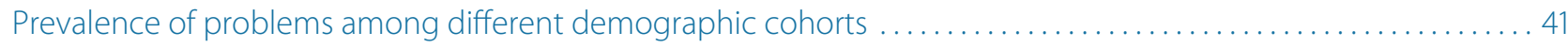

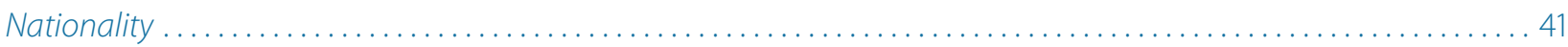

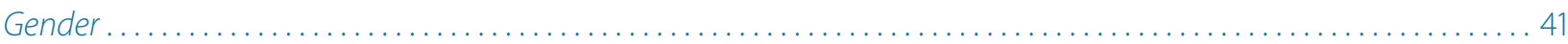

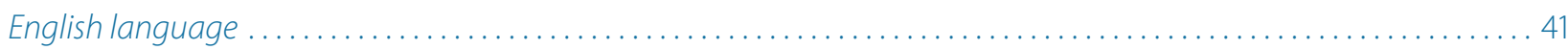

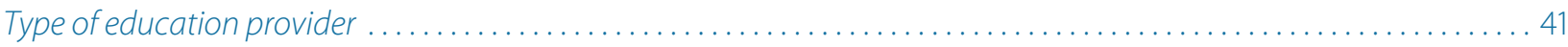

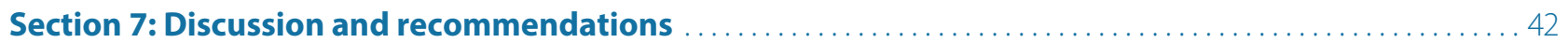

Poor conditions and exploitative practices were substantially more common in share houses - by far the most prevalent first accommodation for international students. ................................. 42

There is a pressing need for improved information and expanded housing services, pre-departure and in

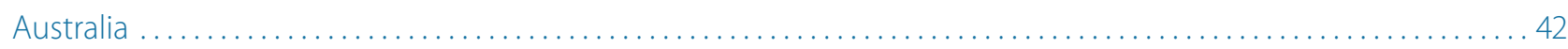

Exploitation can be reduced through increased accountability and improved government regulation ......... 43

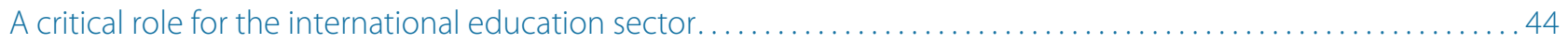

Harnessing the leverage of social media and peer-to-peer sharing websites $\ldots \ldots \ldots \ldots \ldots \ldots \ldots \ldots \ldots \ldots$

Addressing problems in homestays and commercial student accommodation......................... 45

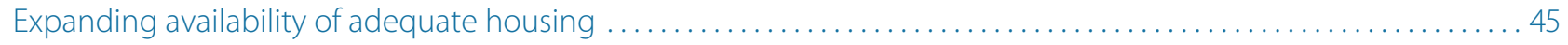

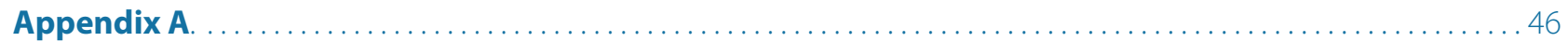




\section{Acknowledgements}

We acknowledge the Traditional Owners of the land on which this report was researched and written, the Gadigal People of the Eora Nation. We acknowledge that sovereignty was never ceded, and pay our respects to Elders past, present and emerging.

StudyNSW provided generous financial support for this research through its Partner Project Scheme. The authors greatly appreciate the guidance and ongoing support for this work that Toshi Kawaguchi and Peter Mackey have consistently provided throughout the life of the project, and for their genuine commitment to international student wellbeing in NSW.

The authors are deeply grateful for the significant contributions of the staff on the Information for Impact project. We thank Sonja Duncan (SD Strategies) for her expert project coordination, including skillfully liaising with project partners and stakeholders throughout the project, managing, conducting and analysing the international student focus groups across multiple locations, for contributing to project presentations, budgets and reporting and for her warmth and good humour throughout the project. Elizabeth Moss developed and expertly implemented the social media survey dissemination strategy, and executed other online promotion and administrative support. Angela Kintominas, Research Associate at the Migrant Worker Justice Initiative (MWJI), provided a comprehensive review of relevant studies and an insightful synthesis of information provided to international students from various sources, as well as contributing to project management. Joshua Kan, Research Associate at MWJI, provided superb editorial assistance and the graphic representation of the data in this report. Freelance social researcher and data analyst Christine Eastman (christine@christineeastman.com) provided insightful expert data analysis with dedication and great patience. Dong-Ju Lee managed the elegant and meticulous setup of the survey in Qualtrics and, with Yiran Li, edited and re-coded open response data.

Many colleagues within UTS and UNSW Sydney have supported the project and committed time to ensuring its success. We especially thank the Faculties of Law of our universities for their continuing support of the Migrant Worker Justice Initiative. The authors deeply appreciate the personal support for the project provided by UNSW PVC(International) Laurie Pearcey, Charlotte Long (UNSW Head of International Student Experience), Jennifer Ford, Gabrielle Dunlevy and colleagues at the Australian Human Rights Institute, UTS Provost and Senior Vice-President Professor Andrew Parfitt and UTS DVC and Vice-President(International) lain Watt. We thank Alan Morris, Debbie Vadasz and Fiona Board for helpful feedback on early drafts of this report. We are also grateful for the significant contributions and various forms of financial and in-kind support provided by our partner organisations on the project: Fair Work Ombudsman, English Australia, Redfern Legal Centre, International Student Education Agent Association, ISANA NSW, and Council of International Students Australia, as well as project advisors, Australian Taxation Office and the Commonwealth Department of Education.

The authors greatly appreciate the time and effort contributed by the many individuals who assisted throughout the study, including:

- International Student Members of the Participant Recruitment Committee: Sarina Manandhar, Nayonika Bhattacharya, Ashley Liau, Annalyn Violata, Sean Luo, and Fabiola Granja, who assisted with testing the survey in multiple languages, recruitment of international students for focus groups, and dissemination of the survey via social media;

- Sean Xiang Cheng, Work Integrated Learning (WIL) Coordinator, UNSW Masters of Translation and Interpreting and Faramarz Shakibaei, UNSW international student who expertly coordinated translation of the survey into Mandarin and Spanish;

- James Diacoumis and Camila Puntel, who invested significant time and effort in translating the survey to Portuguese, testing the translation and disseminating the survey among the Brazilian community, as well as organising a Brazilian student focus group; 
- Renato Lazari and Isabel Habekost, who generously assisted with testing the Portuguese and Spanish surveys respectively; and

- Unions, NGOs, service providers and universities that distributed the survey to international students.

Most importantly, the authors are deeply grateful to every international student who was willing to share information about their experience in Australia and generously gave their time to participate in a focus group and/ or complete the survey. 


\section{Executive Summary}

\section{Introduction}

In recent years, stakeholders across the international education sector have become increasingly concerned about the mistreatment of international students in housing and at work. In 2018, UNSW Sydney and UTS established a sector-wide consortium to better understand the problems international students encounter, and empirically identify key interventions that would have the greatest impact.' Through StudyNSW's Partner Project Scheme, the consortium established Information for Impact: Enabling education providers to address exploitation of international students in accommodation and at work.

This report establishes a detailed evidence base on international students' housing decisions and experiences in Australia. A second report, to be published in early 2020, will provide findings on international students' experiences of underpayment and other problems at work. A third report, to be published in the first half of 2020, will present the survey findings on interventions that can effectively guide students' decision-making and address problems in housing and work. In doing so, the study provides education providers, government, education agents and legal/tenancy service providers with much needed data to identify the conditions for exploitative conduct that require immediate law and policy reforms. It also seeks to identify the conditions for effective empowerment of international students, including through services delivered by education providers, education agents and government.

\section{Overview of the survey and participants}

The Information for Impact survey was an online anonymous survey conducted by Laurie Berg (UTS), Bassina Farbenblum (UNSW) and independent consultant Sonja Duncan between 9 April and 30 May 2019. The survey was undertaken by 5,968 current international students in Australia. This report is based on survey responses from 2,440 of these, aged 17 and over who received survey questions on housing experiences in Australia (the other survey participants received questions about work). The overwhelming majority of respondents were reporting on recent experiences (78\% arrived since 2017 with 57\% having arrived within a year of the survey).

The overwhelming majority (86\%) were 20 years or older with a median age of 23 . Respondents were nationals of 103 countries, with a quarter from China, followed by 14\% from India. They were students at universities (59\%), vocational and English language colleges (30\%) and university foundation courses (12\%). Approximately two thirds were located in NSW, with 96\% in major Australian cities. For the vast majority, their planned stay was not brief: $69 \%$ planned to stay for more than two years. Among respondents who had arrived at least three months before the survey, two thirds (65\%) had worked in Australia.

\section{Respondents' first accommodation in Australia}

Respondents were asked a set of questions related to their'first accommodation in Australia (not including somewhere you stayed temporarily on arrival)'.

\section{Share houses were by far the most common first accommodation}

Well over a third (36\%) of respondents first lived in a share house, by far the most common first accommodation.

1 The consortium included the Fair Work Ombudsman, English Australia, Redfern Legal Centre, International Student Education Agent Association, ISANA NSW, and Council of International Students Australia, as well as project advisors, Australian Taxation Office and the Commonwealth Department of Education. 
Share houses were most common among both men (37\%) and women (35\%), and for both students studying in private colleges (35\%) and at university (39\%) and regardless of students' intended length of stay. Share houses were the first accommodation for especially large proportions of students from Colombia (51\%), Pakistan (50\%), Nepal (48\%), India (41\%) and Bangladesh (40\%). Almost half of students aged 26-29 first lived in a share house, with proportions decreasing among younger students. A greater proportion of students who had worked in Australia at the time of the survey lived in share houses (39\%) compared with those who had not (31\%).

Approximately one in five stayed with friends and family (18\%), either as guests or in a commercial arrangement, including a greater proportion of respondents who had worked in Australia (22\%) than those who had not (13\%).

Homestays were the first accommodation of around one in ten respondents (11\%), including a higher proportion of women (12\%) than men (9\%). This housing was far more common among students from China (23\%) than other nationalities (7\%) and more common among college students (14\%) than university students (5\%).

Around one in ten respondents (11\%) stayed in university housing on campus. This included particularly large proportions of students from Hong Kong (36\%), USA (39\%), and Singapore (35\%), and a greater proportion of women (13\%) than men (9\%). It was far more common among those planning to stay 3-6 months (27\%) than other periods.

Seven percent of respondents stayed in commercial student accommodation (e.g. Urbanest, lglu), including similar proportions of college and university students. The largest proportions of students whose first accommodation was in commercial student accommodation were from Singapore (22\%), Hong Kong (18\%), Indonesia (12\%), Malaysia (11\%) and USA (10\%).

Around one in seven (14\%) respondents signed a lease directly with an owner or real estate agent in a private rental in their first accommodation. A boarding house (renting a bed in a house with rules they were required to obey) was the first accommodation for $2 \%$ of respondents.

\section{Problems in accommodation}

\section{Poor conditions and exploitative practices were substantially more common in share houses}

Half of all respondents indicated that they had experienced one or more problems in their housing in Australia. These included a range of deceptive practices: accommodation was different to what was described; paying for accommodation that did not exist at all; landlord moved extra people into the accommodation without the student's consent; student was told that the accommodation was 'not ready' and they had to pay extra to stay elsewhere; and landlord failed to provide their correct contact details. It also included several financial and other exploitative practices (landlord required the student to pay a lot of money up front; landlord would not return some or all of the student's bond; landlord suddenly increased the rent in the middle of a rental period; and unfair eviction). Students also experienced poor living conditions (overcrowded accommodation; accommodation that was unsafe or not fit to live in; and landlord would not make repairs). Students reported experiences of intimidation, harassment or sexual harassment by a landlord or tenant.

Every one of these problems (except sexual harassment) was experienced by more international students living in a boarding house or share house for their first housing than any other type of housing.

\section{Problems in share houses were entrenched and persistent, and were not confined to share houses organised from overseas or to students' first accommodation}

Almost half of respondents whose first accommodation was in a share house arranged it after arrival (46\%), including substantially greater proportions of some nationalities, e.g. Indian and Nepalese students. The prevalence of most problems, including deception and poor housing conditions, did not diminish among those who organised their accommodation after arrival. 
Almost two-thirds of respondents (61\%) moved housing during their time in Australia. Overall, the proportion of students who experienced each type of problem in their first accommodation was similar to the proportion who experienced the problem in any later accommodation. Though the survey did not record respondents'type of accommodation for later housing, most of these were likely share houses as students moved from initial more secure housing to a share house, and/or from one share house to another. The proportion of participants who indicated that they experienced each problem in a share house in their first accommodation is, therefore, likely the tip of the iceberg of problems experienced in share houses overall.

\section{Problems were most commonly experienced among respondents who organised their share house through social media or a peer-to-peer sharing website}

Among those whose first accommodation was in a share house, over half organised it through a peer-to-peer sharing website (such as Gumtree, Flatmates.com.au or the Chinese language website/app, Sydney Today) (28\%) or social media (including Facebook and WeChat) (23\%). Among those who used these platforms to organise a share house, around half did so from their home country and half used the platforms in Australia. Deception, overcharging money upfront and poor living conditions were far more common among those who used these channels to organise their share house. This was the case regardless of whether they organised their share house from their home country or in Australia.

Among respondents whose first accommodation was in a share house, 98\% organised this alone without assistance from their university or college. The findings underscore the need for education providers to provide housing services that assist international students to find decent share houses and evaluate housing offered online, both offshore and onshore.

\section{Problems in homestays and commercial student accommodation}

Although the greatest number of international students who experienced problems were in share houses and boarding houses, some other types of housing also warrant attention and reform. For example, many problems were also experienced by a substantial proportion of international students in homestays, including overcrowding, accommodation that was unsafe or not fit to live in and intimidation or harassment. Those whose first accommodation was in commercial student accommodation reported a comparatively high incidence of paying for non-existent accommodation, unexpectedly finding their accommodation was 'not ready' and having to stay somewhere else (higher than for any other accommodation type) and accommodation that was overcrowded, unsafe or not fit to live in.

\section{Problems were experienced similarly among university and college students, with some variations between nationality groups}

Students at private colleges experienced problems in almost the same proportions as university students. Most problems were reported by similar proportions of men and women.

However, there were greater disparities among different nationalities. Paying for accommodation that did not exist was reported by an especially large proportion of respondents from Nepal (20\%), Vietnam (17\%), Bangladesh (13\%) and India (12\%). Overcrowding was reported by particularly high proportions of students from China (21\%), Brazil (18\%), Vietnam (18\%), India (16\%) and Nepal (15\%). Sexual harassment was experienced by respondents in almost all of the top 15 nationalities. Most problems were reported by similar proportions of those with self-reported good English language ability and those with fair or poor English. 


\section{Recommendations}

The findings support many of the recommendations that appear in the recent UNSW Human Rights Clinic report, No Place Like Home: Addressing Exploitation of International Students in Sydney's Housing Market. ${ }^{2}$ In particular, the findings confirm the need for increased access to quality affordable housing, including university housing and crisis accommodation. The data underscores the importance of improved access to information and substantially increased availability of services - both housing services that assist students to find decent share house accommodation and legal advice to empower students to enforce their rights. These services should be provided by universities, and by state and local governments for non-university students.

There is a clear need for increased government enforcement to break cycles of impunity and hold accountable the many accommodation providers who are repeatedly engaging in deceptive and exploitative practices in relation to international students. At the same time, the data indicates a pressing need to strengthen international students' legal rights and access to justice, particularly in share houses, boarding houses and elsewhere in the marginal rental sector. This includes, for example, extending the application of tenancy laws to all share house tenants and ensuring international students can easily reclaim their bond or other large sums of money improperly demanded by the housing provider upfront. Peer-to-peer sharing platforms like Gumtree and Flatmates.com.au must play a role in warning international students about potential dangers and removing deceptive advertisements.

Exploitative housing situations substantially undermine the international student experience in Australia. They impact international students' emotional, physical and financial wellbeing, and can seriously affect their studies. The pervasive nature of the problems identified in this report demands an investment of resources in timely and systemic responses by education providers, government and all stakeholders across the international education sector. 


\section{Section 1: Introduction}

In recent years, stakeholders across the international education sector have become increasingly concerned about the mistreatment of international students in housing and at work. International students are already provided with an array of information from various sources, including from their education providers and government, and it is clear that these are not yet generally preventing problems or assisting large numbers of international students to resolve problems and seek redress. Education providers, peak bodies and government are now seeking to understand the drivers of these problems, and to identify effective interventions.

In 2017 and 2018, several empirical studies were published on exploitation of international students at work, establishing that underpayment among these workers is pervasive and, in many cases, severe. ${ }^{3}$ Housing problems encountered by international students in Sydney were the focus of the UNSW Human Rights Clinic report No Place Like Home: Addressing Exploitation of International Students in Sydney's Housing Market. Based on focus groups, interviews and service-provider case data, the report found that education providers and policymakers lack a detailed understanding of precisely where and how different cohorts of international students live, how and when they find their accommodation, the prevalence of the problems they encounter, and their responses to those problems. No large-scale data has been gathered on international students' housing experiences and their ability to seek redress. ${ }^{4}$

In 2018, UNSW Sydney and UTS established a sector-wide consortium to better understand the problems international students encounter in accommodation and at work, and empirically identify key interventions that would have the greatest impact. The consortium included the Fair Work Ombudsman, English Australia, Redfern Legal Centre, International Student Education Agent Association, ISANA NSW, and Council of International Students Australia, as well as project advisors, Australian Taxation Office and the Commonwealth Department of Education.

Through StudyNSW's Partner Project Scheme, the consortium established Information for Impact: Enabling education providers to address exploitation of international students in accommodation and at work - an empirical research project involving four elements: a mapping of information provided to international students on work and accommodation rights; consultations with experts across the sector and among service providers; focus groups with international students in NSW and the ACT; and a large-scale national survey of international students (Australia-wide, but primarily focused on New South Wales). The information mapping, expert consultations, and focus groups were used to inform the design of the survey and analysis of its data.

The findings from the Information for Impact survey, conducted between April and May 2019, will be presented in three reports. The survey was undertaken by over 5,000 international students who were nationals of more than 100 countries, across all states and territories. Participants were randomly allocated to either a set of questions on their experiences in relation to housing or a set of questions relating to their experiences at work. Both groups were then asked detailed questions in order to identify what information and services they would want to receive in each area, including identifying gaps in knowledge of rights, as well as when and how information and services should be delivered for maximum utility.

3 See e.g. Laurie Berg and Bassina Farbenblum, Wage Theft in Australia (2017); Bassina Farbenblum and Laurie Berg, Wage Theft in Silence (2018); lain Campbell, Martina Boese and Joo-Cheong Tham, 'Inhospitable Workplaces? International Students and Paid Work in Food Services' (2016) 51 Australian Journal of Social Issues 279; Stephen Clibborn, 'Multiple Frames of Reference: Why International Student Workers in Australia Tolerate Underpayment' (2019) Economic and Industrial Democracy (forthcoming); Alexander Reilly, Joanna Howe, Laurie Berg, Bassina Farbenblum and George Tan, International Students and the Fair Work Ombudsman (Fair Work Ombudsman, 2017).

4 A number of small studies have been conducted, in addition to broader studies on housing issues affecting vulnerable groups generally. See e.g. Nicole Gurran et al, Informal Accommodation and Vulnerable Households: Scale, Drivers and Policy Responses in Metropolitan Sydney (Sydney Policy Lab and the Urban Housing Lab, April 2019) 43, 46; Sarah Elisabeth Judd, 'Housing Trajectories of Chinese International Students in Sydney, Australia' (Masters Thesis, The University of New South Wales, 2013) 119; Sharon Parkinson et al, Navigating a Changing Private Rental Sector: Opportunities and Challenges for Low-Income Renters (Australian Housing and Urban Research Institute, July 2018) 75. 
This report focuses on international students' housing experiences and decisions. A second report, to be published in early 2020, will provide findings on international students' experiences of underpayment and other problems at work. A third report, to be published in the first half of 2020, will present the survey findings on interventions that can effectively guide students' decision-making and address problems in housing and work.

This report is based on survey responses of 2,440 international students who received the set of survey questions on housing. Section 2 provides an overview of the survey content and methodology, including dissemination methods. Section 3 sets out the demographics of survey participants, including their type of education provider and whether they had worked in Australia. Section 4 addresses participants' first housing in Australia, including the type of housing, when and how participants organised it, and whether and when they moved to other housing. Section 5 and 6 set out findings in relation to participants' experience of problems and examine the relationship between problems and other factors. This includes different experiences of mistreatment among different demographic cohorts, and among different housing features including type of housing, and when and how students found their housing. It focuses in particular on share houses which are the most common accommodation type and also the most problematic.

In establishing a detailed evidence base on the housing problems international students encounter, this report provides education providers, government, education agents and legal/tenancy service providers with much needed data identifying the conditions for exploitative conduct that require immediate law and policy reforms and expanded and improved international student services, as identified in the Discussion and Recommendations in Section 7.

Exploitation will not be ameliorated without effective empowerment of international students. The survey was driven by this objective in two key ways. First, rather than merely gathering information about participants, it improved international students' understanding of housing rights by providing correct explanations to questions about housing rights after participants provided their response. Second, the survey sought to place the experiences and views of international students at the centre of policy development and services affecting them, gathering large scale data to replace assumptions about them as a cohort with their direct and differentiated voices. In doing so, this report lays the foundation for education providers and government to develop more targeted interventions for international students that directly respond to their lived experiences. 


\section{Section 2: Methodology}

The Information for Impact survey was an online survey conducted by Laurie Berg (UTS), Bassina Farbenblum (UNSW) and independent consultant Sonja Duncan between 9 April and 31 May 2019. The survey was anonymous and open to any international student in Australia who was 17 years or older at the time of the survey. It was hosted on the Migrant Worker Justice Initiative website (www.mwji.org). The survey could be completed on a mobile device or a computer.

Before commencing the survey, participants were provided with information about the survey and how their data would be used, to which they could consent through their participation in the survey. ${ }^{5}$ After completing the survey, participants were invited to enter a separate prize draw to win a $\$ 500$ voucher or one of ten $\$ 100$ vouchers from Coles Myer. They were asked for their phone number for the purpose of advising winners of the prizes. There was no way to connect the phone number provided in the prize survey with answers provided to the Information for impact survey which remained strictly anonymous.

The survey was available in four languages: English, Mandarin, Portugese and Spanish. Each translation was checked by a different native speaker of that language.

\section{Survey content and structure}

The survey contained 45 multiple choice questions, in addition to a number of follow-up questions. A small number of questions allowed open answers, mostly where respondents selected 'Other' among multiple choice options. The survey instrument is available at https://www.mwji.org/information4impact.

Participants were randomly allocated to either a 'Work version' or a 'Housing version' of the survey. Similar sets of questions across both versions addressed participants' personal characteristics, responses to problems, and views on the information and service needs of international students. Table 1 sets out the overall structure of the survey.

Table 1. Structure of survey questions

\begin{tabular}{|c|c|}
\hline Housing version & Work version \\
\hline \multicolumn{2}{|c|}{ course of study, and whether worked in Australia } \\
\hline First housing in Australia & Problems with work \\
\hline Problems with first and later housing & Knowledge of work rights \\
\hline \multicolumn{2}{|c|}{ Whether participants sought information/help for problems } \\
\hline Information and services that would help international students avoid problems at work/housing \\
\hline Knowledge of tenancy rights & Knear of arival in Australia, geographic location, education \\
\hline
\end{tabular}

5 Ethics approval for this research was obtained from UNSW Human Research Ethics and Compliance (HC15861) which was ratified by UTS Human Research Ethics Committee (ETH16-0368). 
Findings on participants' experiences of problems at work will be published in a separate report in 2020. A further report in 2020 will cover findings on participants' responses to problems and where they went for help, as well as questions on the type of information and services that would assist international students to avoid these problems in the future.

This report is based on a sub-set of 3 sections within the survey, for respondents who received the 'Housing version':

1. Participants' personal characteristics including nationality, type of education provider, course of study, location and year of arrival.

2. Characteristics of participants' first accommodation in Australia, including type of housing, when they organised the accommodation and why, and how they found it.

\section{Participants' experience of problems with their housing}

\section{Survey dissemination}

Participants were recruited through various channels including emails, social media, websites and flyers/posters at various locations and events. These included:

1. Social media. The survey was regularly posted on 115 travel, cultural and international student-based Facebook groups, as well as a dedicated Facebook page for the survey. It was also promoted via Instagram, Linkedln and WeChat. Where possible, posts were made in the relevant languages for each group. Close to 23,000 people were reached through two Facebook advertisements across Victoria, New South Wales, Queensland, Western Australia and South Australia.

2. Email. A MailChimp campaign containing a link to the survey was distributed to over 900 contacts across the international education sector. A link to the survey was distributed by email to international students by several education providers.

3. Flyers/posters at various international student events. These included the City of Sydney Lord Mayor's Welcome for International Students, an event for International Student Ambassadors and an event for the international education sector hosted by the Insider Guides.

4. The survey also received coverage, with a link, in a number of news outlets, including the Chineselanguage outlet, Sydney Today, and SBS radio.

Several Project Partner organisations assisted with distribution of the survey through their networks. StudyNSW disseminated information about the survey through their communications with international students and stakeholder community.

An International Student Participant Recruitment Committee was also established to assist with dissemination of the survey through student groups, direct emails and social media outlets including WeChat. Members of the Committee included international students from China, Nepal, India and the Philippines, who were remunerated.

\section{Survey participants}

There were 5,968 individuals who entered responses across the Housing version and Work version of the survey. Of these, 843 responses were removed due to completion of less than 10\% of the survey. A further 61 respondents were removed who took fewer than 11 minutes to complete the survey, leaving 5,064 valid responses. This included 152 respondents whose first education provider in Australia was a high school. Given the low number in this cohort, and their potentially different concerns, the decision was made to exclude them from the analysis, leaving 4,912 respondents in the overall sample. Within this sample, 2,440 respondents received the Housing version of the survey. It is this sample that forms the basis of this report. 
Participants were free to stop the survey at any time. As some participants exited the survey at different points before the end, the number of respondents varied between questions. In addition, some follow-up questions were only shown to participants who selected particular responses.

\section{Methodological limitations}

The survey has a number of methodological limitations. Because the survey was anonymous it is not possible to know whether any participants completed the survey more than once from different devices (it was not possible to complete it more than once from the same device). It is also not possible to verify the accuracy of information provided by participants, and it would have been possible for participants to choose random answers because they wanted to complete the survey quickly in order to enter the prize draw. Those participants motivated to complete the survey quickly may have also been influenced by the order of possible responses (reading or selecting those at the top). These risks were mitigated in two ways. First, the order of responses was randomised where relevant. Second, participants who completed the survey in under 11 minutes, and those who completed less than 10\% of the survey, were excluded from the analysis. There were no strong incentives for other participants to provide inaccurate information or to repeat the survey multiple times. If this occurred, it is likely to have involved only a small number of participants. There was also a further risk that participants may have been afraid to disclose true information. This risk was mitigated by making the survey entirely anonymous.

Overall, these risks appear to have been largely mitigated, as evidenced by the broad consistency of demographic profiles and attitudes expressed in response to questions that were common to the Housing version and Work version of the survey, to which participants were randomly allocated.

A further limitation may have arisen from a key method of distribution of the survey. Reliance on primary promotion through Facebook, Instagram, WeChat, Linkedln and Sydney Today may have contributed to overrepresentation of international students who regularly use these platforms. This risk was somewhat mitigated through distribution through other channels including events attended by international students, online media (including SBS), StudyNSW and other newsletters, and education provider emails to international students (see Survey Dissemination above for further detail). Concerns about weak English-language skills were mitigated by translating the survey into Mandarin, Spanish and Portguese. However, the survey was not available in all languages spoken by international students in Australia, and the survey may not have been accessible to some native speakers of other languages whose English is very poor. It is also possible that certain words or phrases in translated versions may have been understood differently in different languages, or may not have had a culturallyunderstood equivalent.

It is possible that participation was higher among international students who were more motivated to share information on poor workplace or housing experiences, or to assist other international students to avoid problems. The authors sought to limit this possibility by offering a number of substantial prizes to create a different incentive for participation among a broader group. At the same time, it is possible that international students experiencing financial stress were more likely than others to be motivated to complete the survey by the possibility of receiving prizes. Finally, there was an over-representation among participants of international students at UNSW, UNSW Global, UTS and UTS Insearch. This is likely to be a result of particularly effective institutional survey dissemination and potentially greater participant trust in, or identification with the authors because of their affiliation with those institutions.

Taking these considerations into account, and considering the impracticability of random sampling among international students in Australia, the authors determined that the survey and selected distribution methods remained an effective way to access large numbers of diverse international students, especially those studying at smaller education providers who have historically been difficult to reach. 
This section sets out the personal characteristics of the 2,440 respondents who participated in the Housing version of the survey.

\section{Age at time of survey}

All survey participants were required to be 17 years or older at the time of the survey. The median age of respondents was 23 . Over half of respondents (53\%) were aged between 20 and 25 years old. A third (34\%) were older than 25 . Only $14 \%$ were younger than 20 years old.

Figure 1. Respondents' age at time of survey $(n=2,440)$

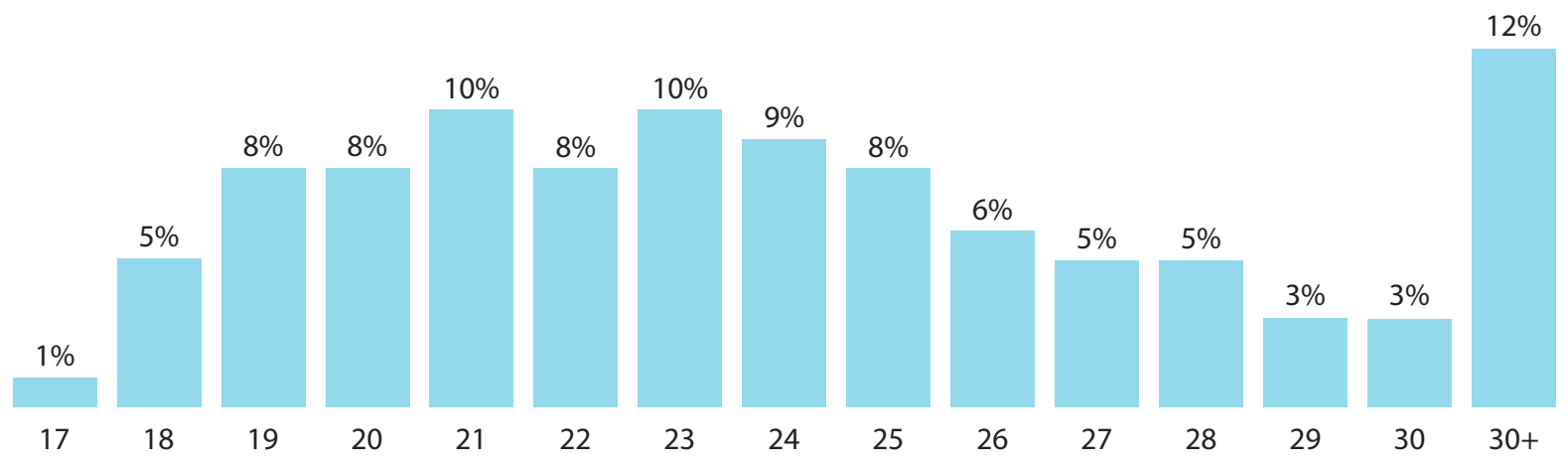

\section{Nationality}

Respondents were nationals of 103 countries. A quarter (25\%) of all respondents were from China, ${ }^{6}$ followed by 14\% from India, and 8\% from Nepal. The 16 largest nationality groups also included students from Latin America (Brazil (4\%) and Colombia (3\%)), South East Asia (Indonesia (4\%), Vietnam (4\%), Malaysia (3\%), Philippines (3\%), Singapore (2\%)), South Asia (Pakistan (2\%), Bangladesh (2\%), Sri Lanka (2\%)), East Asia (Hong Kong (3\%), South Korea $(1 \%))$ and North America (United States of America (3\%)).

The overwhelming majority of respondents were reporting on recent experiences: $78 \%$ had arrived in Australia since 2017 and $57 \%$ arrived within a year of the survey.

6 'China' may include some Taiwanese students. In the initial stages of the survey there was an inadvertent mechanical omission of a separate category for Taiwan, however this error was corrected during the survey. 


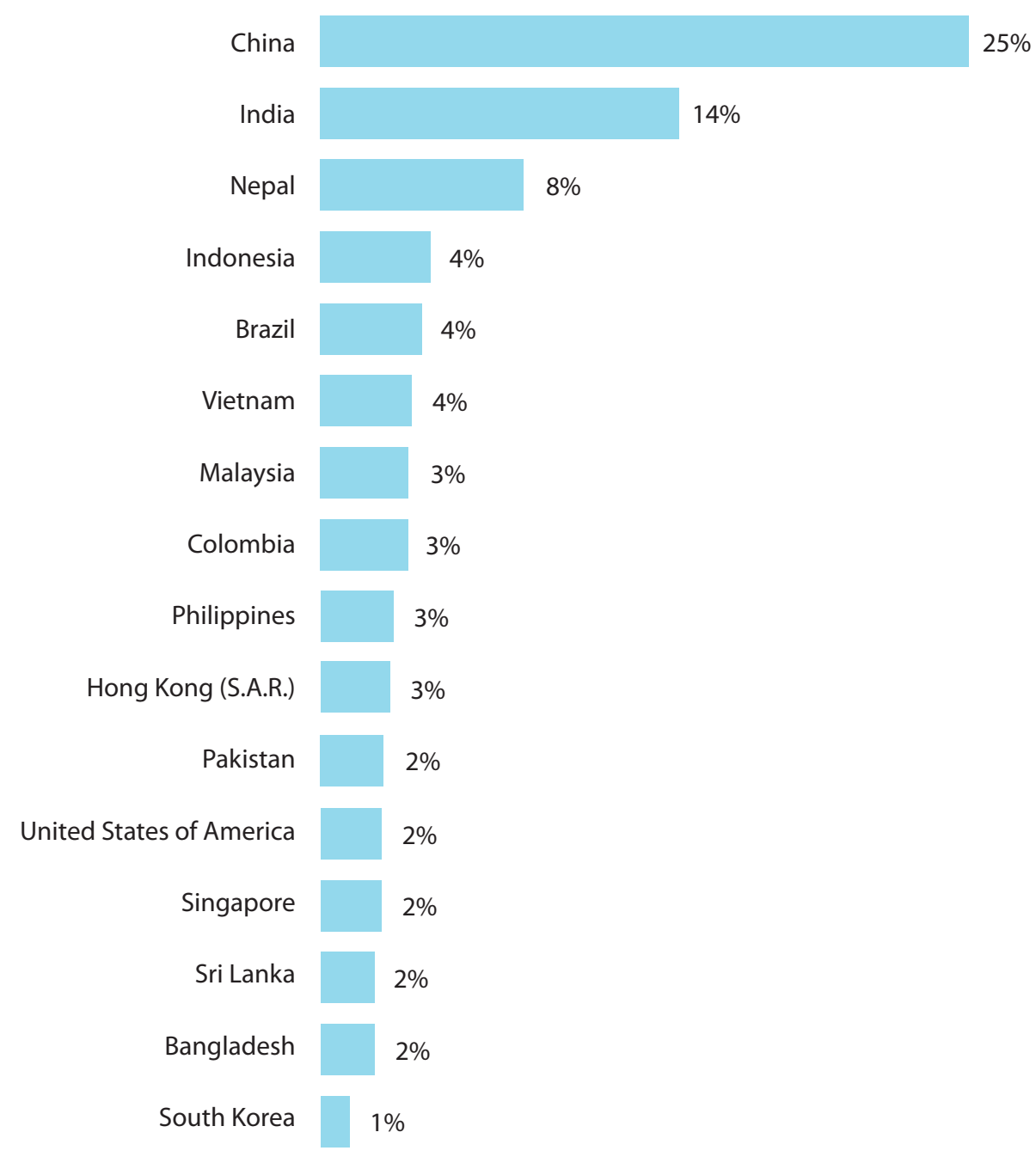

\section{Other demographics}

A larger proportion of respondents were female (59\%). Six respondents specified their gender as 'other'.

The overwhelming majority (96\%) held a student visa as their first visa. Two percent held a Working Holiday or Work and Holiday visa.

Respondents were asked to rate their English language ability. Three quarters (74\%) rated it as very good or good; $24 \%$ indicated that it was fair; $2 \%$ rated it as poor or very poor.

\section{Year of arrival and planned length of stay}

The overwhelming majority of respondents were reporting on recent experiences. Over three quarters (78\%) arrived in Australia since 2017, with 57\% having arrived within a year of the survey. 


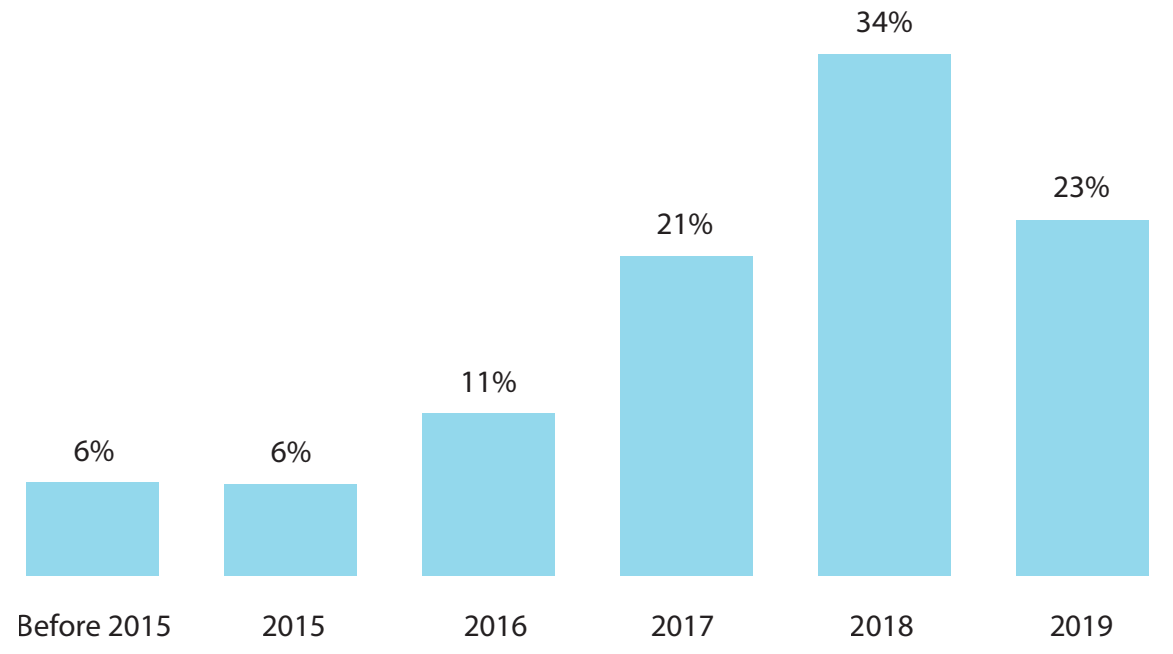

For the vast majority of respondents, their planned time in Australia was not a brief stay. Over two-thirds of respondents (69\%) planned to stay in Australia for more than two years, with a further 14\% planning to stay between 19 and 24 months. Only 17\% of respondents were planning to stay for 18 months or less.

Figure 4. Respondents' total planned length of stay in Australia $(n=2,440)$

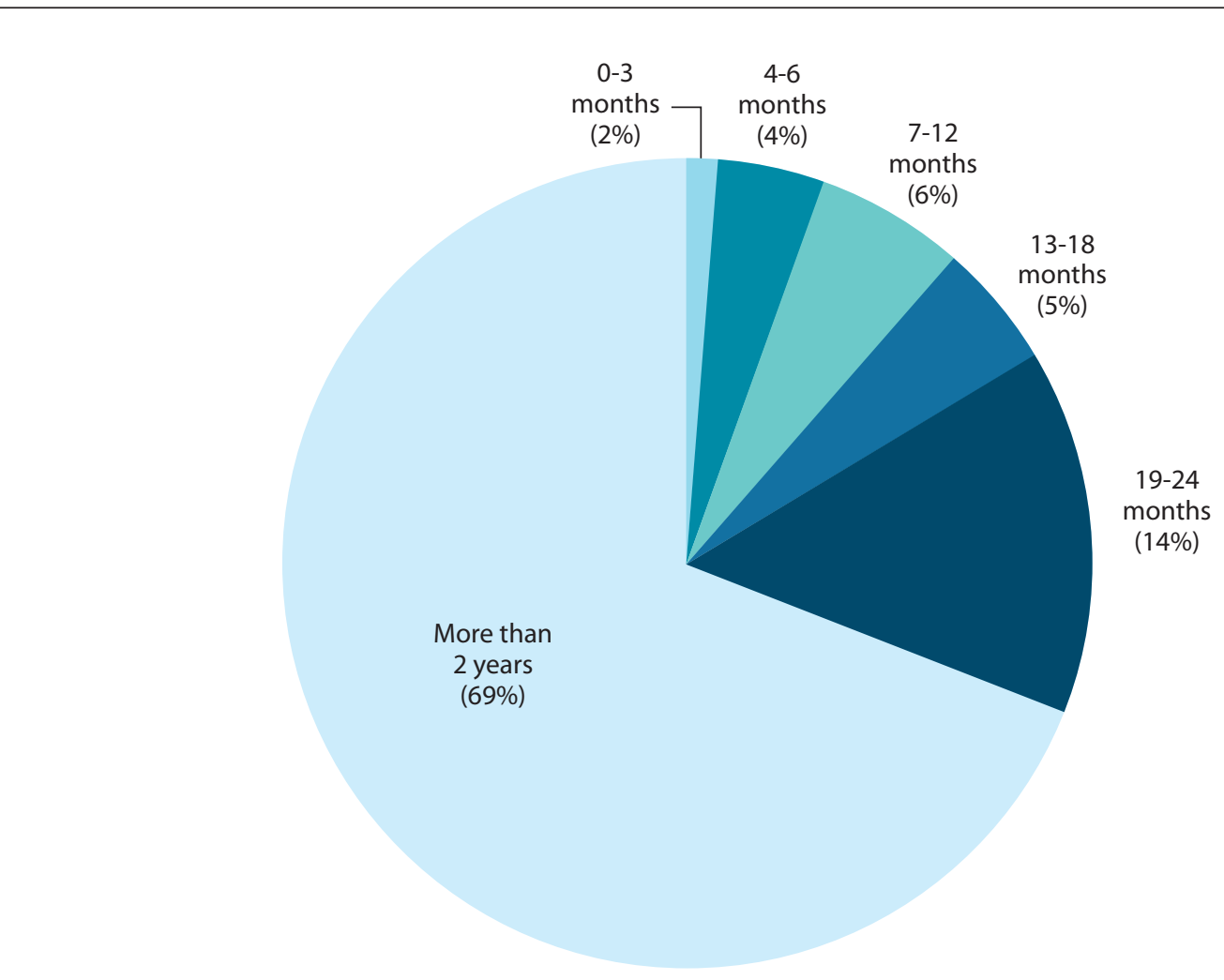

Well over $80 \%$ of students in all programs of study (including English language and vocational courses) planned to stay in Australia for longer than a year, and the large majority of students in all programs planned to stay more than 2 years. 


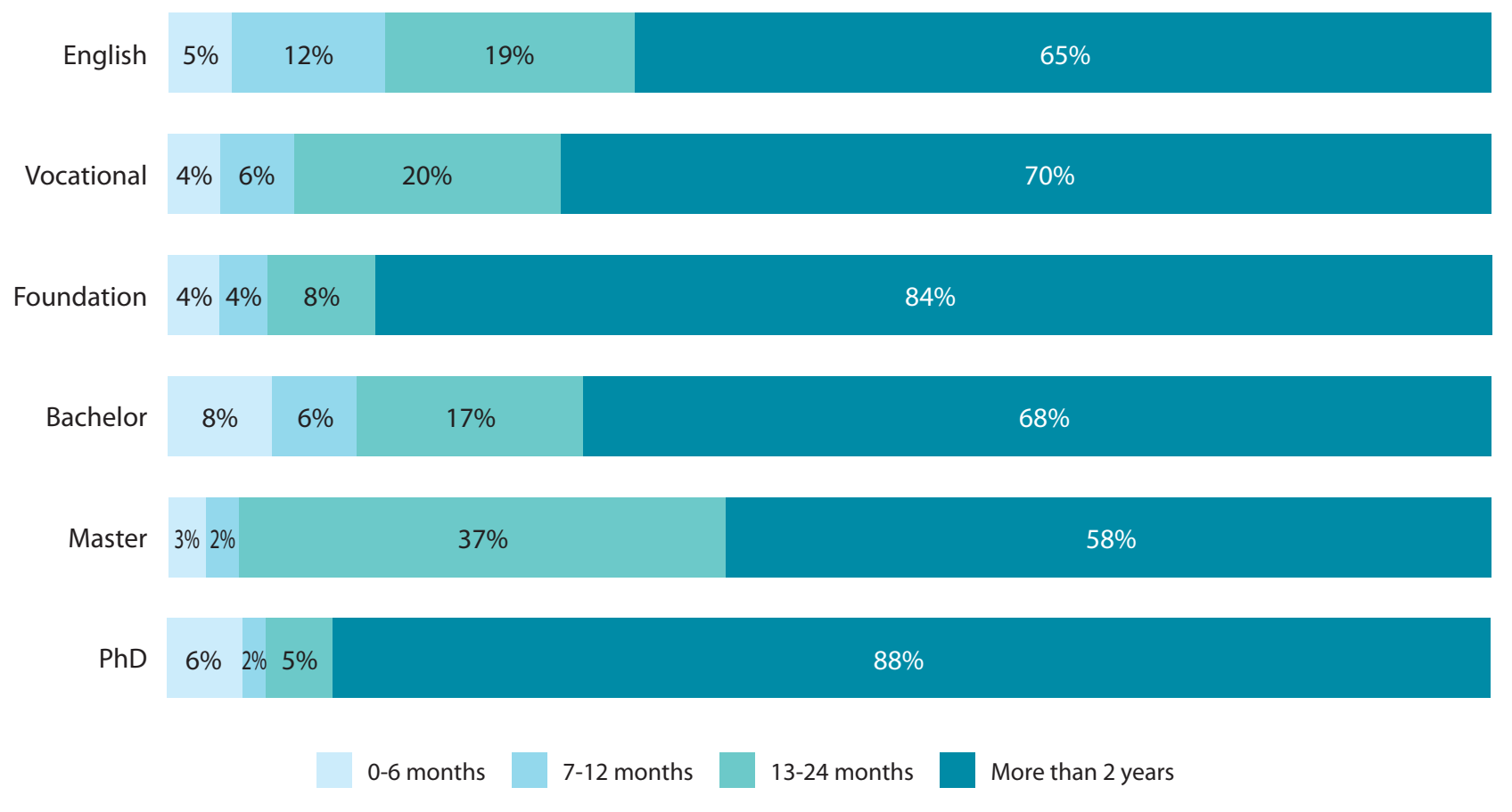

\section{Whether respondents had worked in Australia}

Among respondents who had arrived at least three months before the survey, two thirds (65\%) had worked in Australia. This figure underrepresents the proportion of respondents who would work during their studies in Australia as some respondents may not have worked yet at the time of the survey but would do so at a later point in their stay (bearing in mind that 57\% arrived within a year of the survey).

\section{Respondents' type of first education provider and first program of study in Australia}

\section{Type of first education provider}

For almost a third of respondents (30\%; 729 participants), their first education provider was a private college including a vocational or English language college. For a further 12\% (291 participants), their first education provider was a university foundation studies provider. For the remainder (59\%; 1,433 participants), their first education provider was a university. 


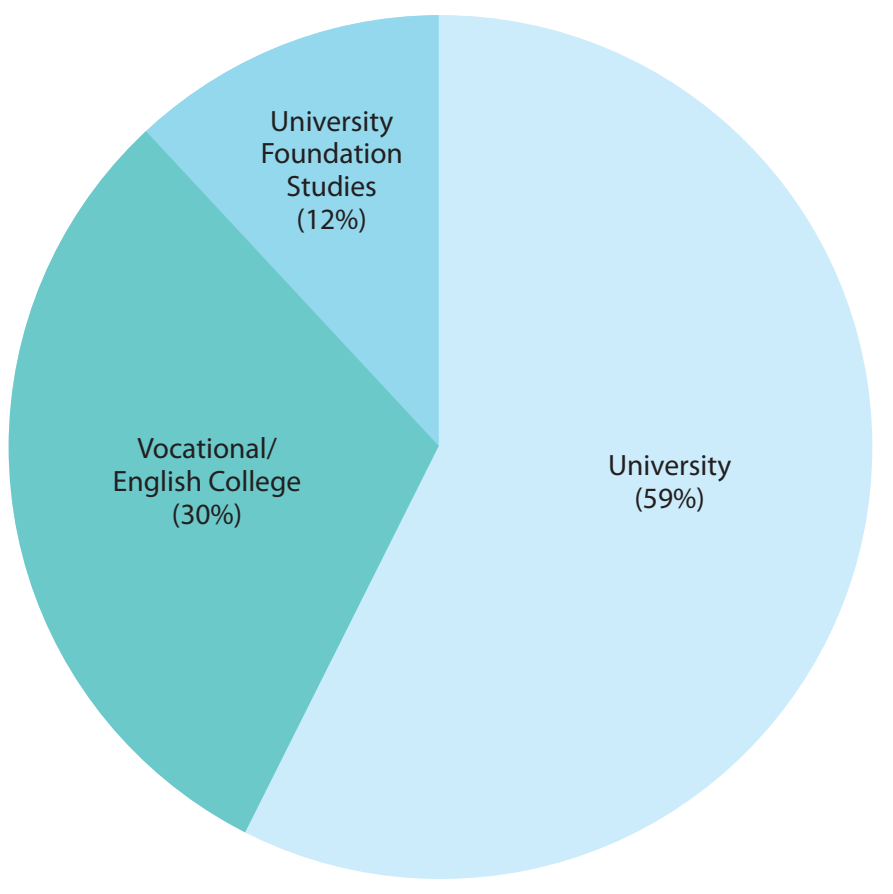

\section{First program of study}

The largest cohort of respondents (37\%) were first enrolled in a bachelor degree program. Over a fifth of all participants had already completed an undergraduate degree overseas and were first enrolled in either a masters program (17\%) or PhD program (5\%).

Two-fifths of respondents were first enrolled in non-degree programs including 17\% in English language courses, $12 \%$ in vocational courses, and $12 \%$ in Foundation studies.

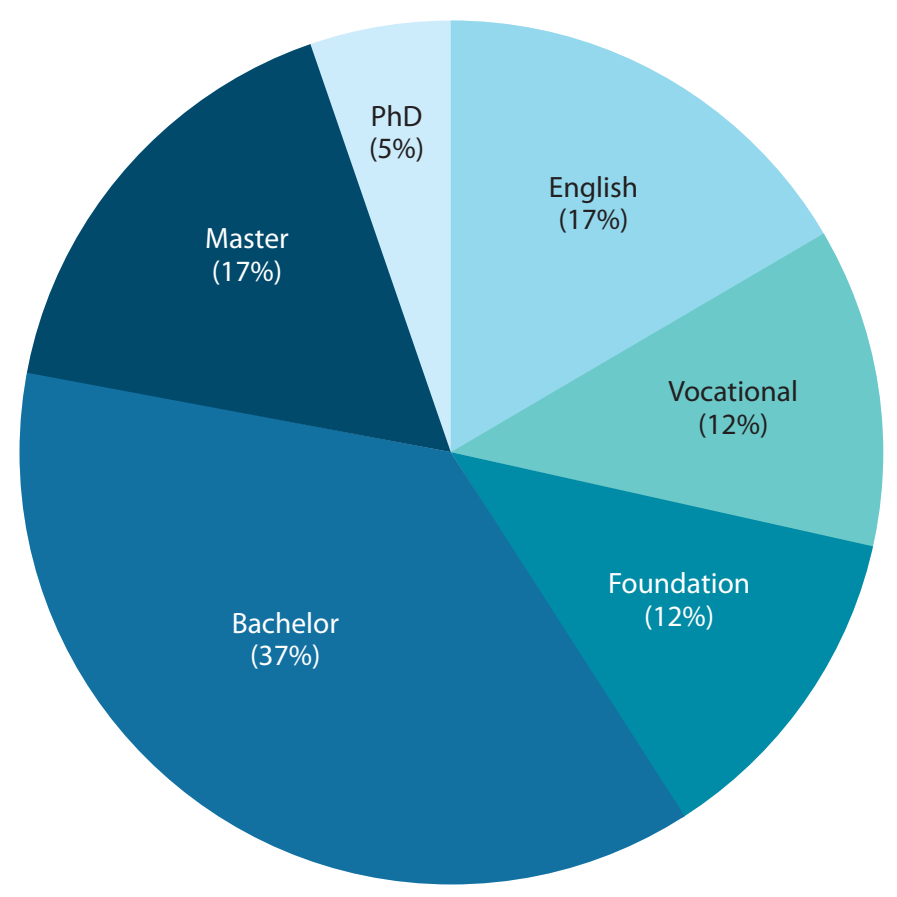




\section{Geographic location}

As the study was funded by StudyNSW, survey dissemination activities focused primarily on New South Wales (NSW). However, the survey was open to any international student in Australia. Respondents were asked where they lived in their first accommodation in Australia. Approximately two thirds (69\%) were located in NSW, followed by $15 \%$ in Victoria, 9\% in Queensland and the remaining 7\% across the other states and territories. Housing is governed by state and municipal laws, with enforcement by state and local government agencies. As a result, laws, policies and practices may vary between states. Where this report references tenancy laws it does so for NSW.

Figure 8. Respondents'state/territory of first residence $(n=2,440)$

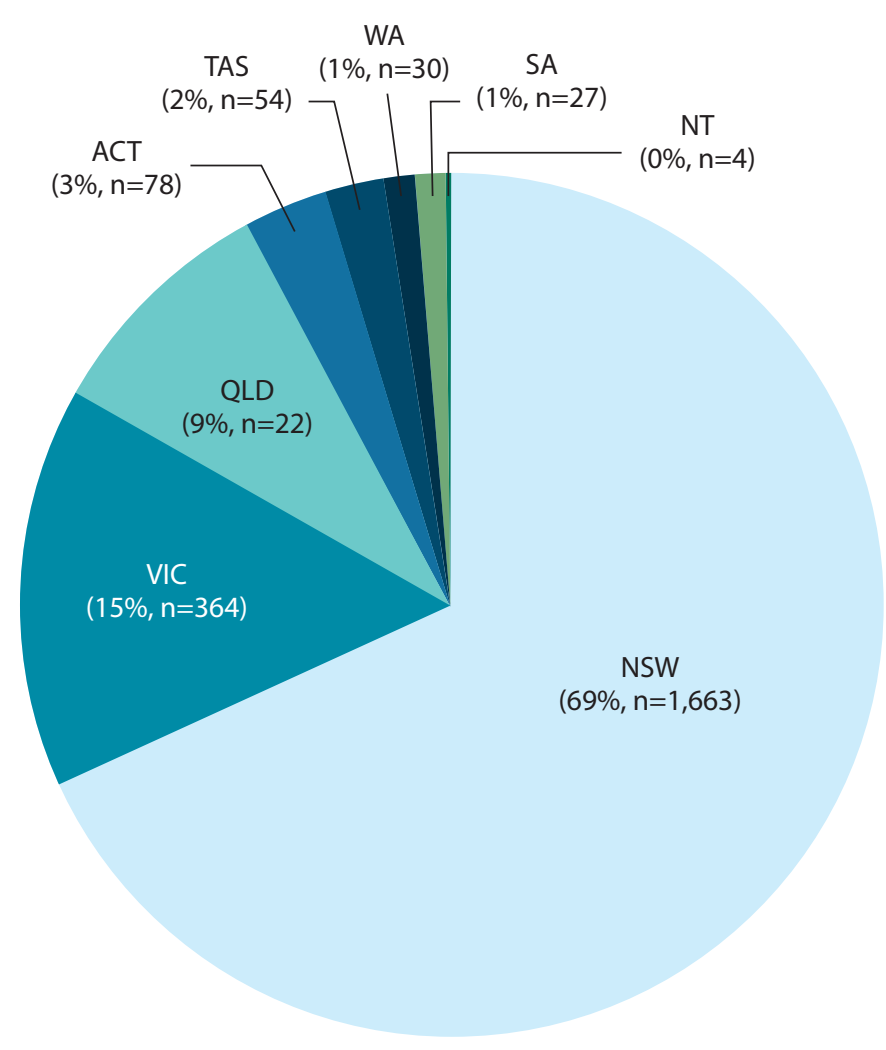

The overwhelming majority of respondents (96\%) were located in a major city. This included 64\% in Greater Sydney, 15\% in Greater Melbourne and 8\% in Greater Brisbane. Greater Hobart, Perth, and Adelaide were home to $4 \%$ of respondents.

Fewer than 4\% were located in 'inner regional Australia' (3\%) or 'outer regional Australia' (0.5\%).

7 The Australian Bureau of Statistics includes in its geographical classifications a Remoteness Structure, which divides Australia into five classes of remoteness according to their relative access to services (see http://www.abs.gov.au/websitedbs/D3310114.nsf/home/remoteness+structure). We used a correspondence file supplied by the ABS to code locality information collected in the survey (locality name and/or postcode) to the ABS Remoteness Structure for each participant. 


\section{Section 4: Respondents' first housing in Australia}

\section{Type of first housing}

Respondents were asked to specify their'first accommodation in Australia (not including somewhere you stayed temporarily on arrival).' As shown in Figure 9 below, a far greater proportion had their first accommodation in a share house (36\%) than any other type of accommodation. ${ }^{8}$ Figure 10 below reveals that respondents whose first accommodation was in a share house included $19 \%$ of $18-19$ year old respondents, rising steadily with age to $27 \%$ of 20-21 year olds, 38-39\% of 22-25 year olds, and 47-49\% of those aged 26-29 years old.

Almost one in five stayed with friends and family (18\%), either as guests or in a commercial arrangement. Only $14 \%$ of respondents signed a lease directly with an owner or real estate agent in a private rental in their first accommodation. Smaller proportions of students stayed in student housing. This includes $7 \%$ in commercial student accommodation (e.g. Urbanest, Iglu) and $11 \%$ in a residential college on a university campus (15\% of all university students). Around one in ten respondents stayed in a homestay (11\%) and $2 \%$ stayed in a boarding house. ${ }^{9}$

Figure 9. Participants' first accommodation in Australia ( $n=2,399)$

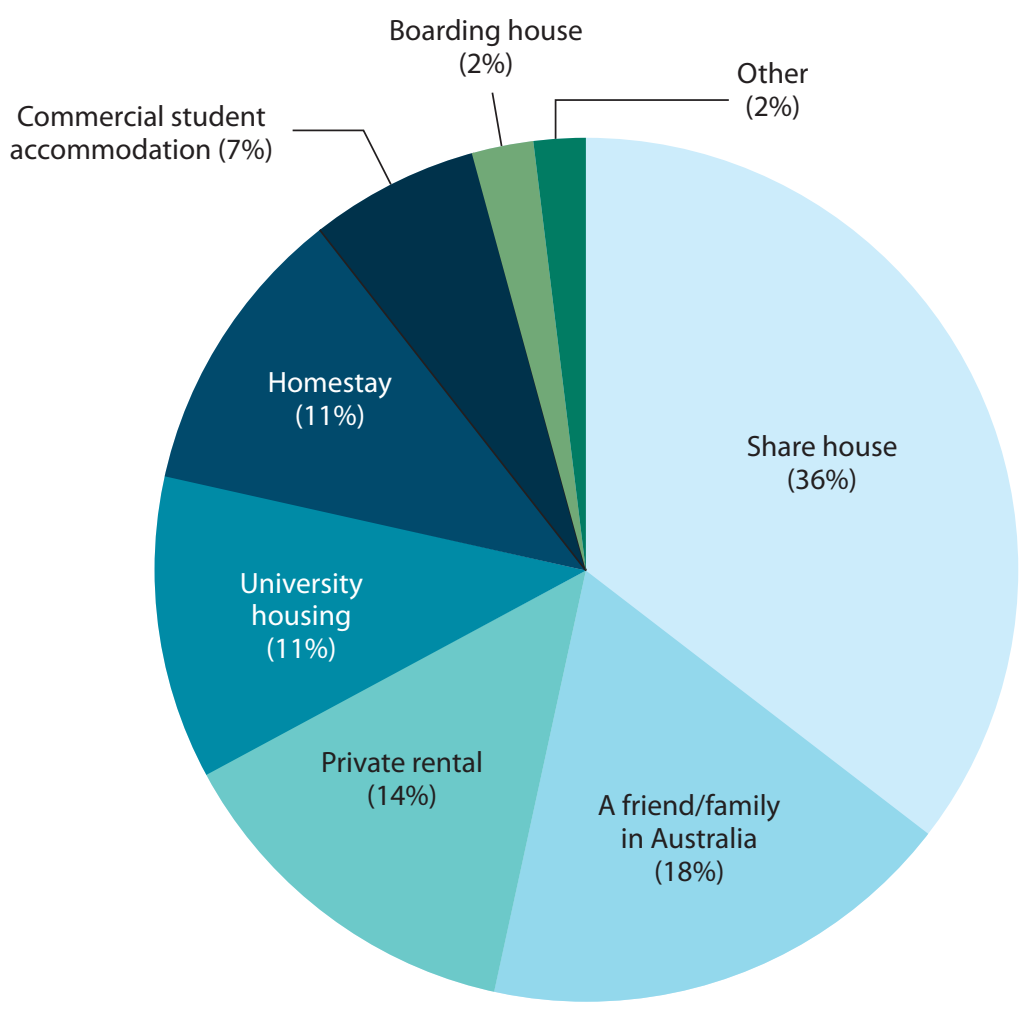

8 A 'share house' was described in the survey as 'renting a room in a private house or apartment shared with other tenants'.

9 A 'boarding house' was defined in the survey as 'renting a bed in a house with rules you were required to obey'. 


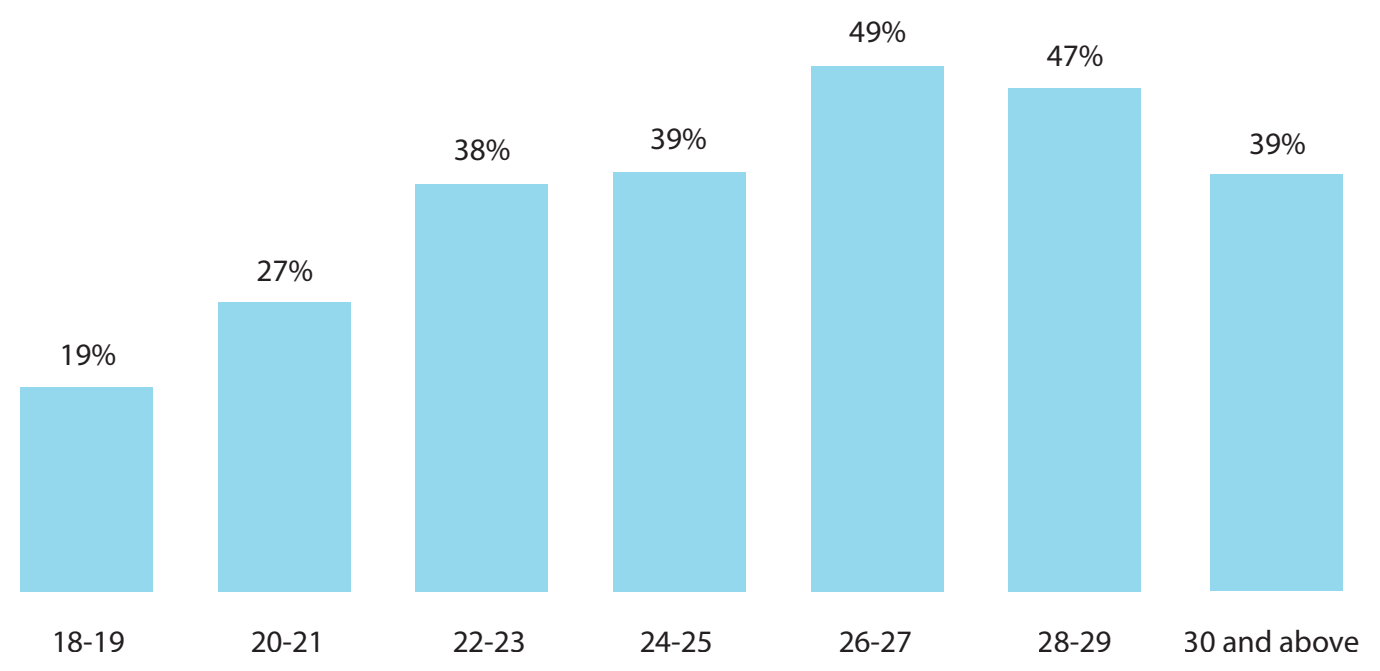

A far greater proportion of respondents had their first
accommodation in a share house (36\%) than any
other type of accommodation

\section{Nationality}

A particularly large proportion of certain nationalities lived in a share house as their first accommodation in Australia. These included students from Colombia (51\%), Pakistan (50\%), Nepal (48\%), India (41\%) and Bangladesh (40\%). In contrast, share houses were the first accommodation of far smaller proportions of students from Hong Kong (12\%), USA (17\%), and Singapore (16\%). Among these students, a far greater proportion stayed in residential colleges on campus (36\%, 39\% and 35\% respectively) than other nationalities (average 11\%).

Nationalities with the highest proportion of students in commercial student accommodation included Singapore (22\%), Hong Kong (18\%), Indonesia (12\%), Malaysia (11\%) and USA (10\%).

Homestay was far more common among students from China (23\%) than other nationalities (7\%). 


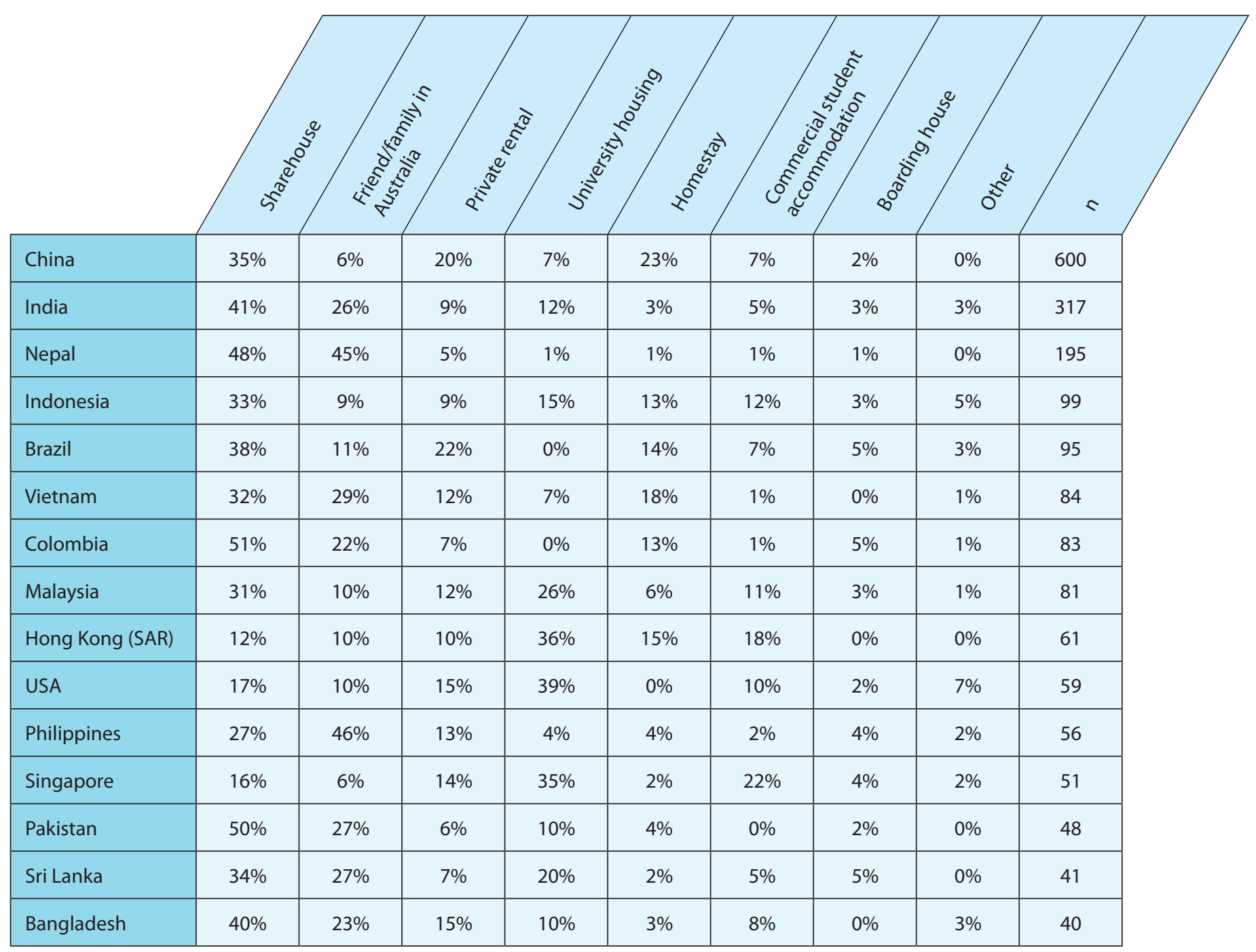

\section{Gender}

Share houses were by far the most common first accommodation for both men (37\%) and women (35\%). A slightly higher proportion of women lived in university housing (13\% vs $9 \%$ of men), homestays ( $12 \%$ vs $9 \%$ of men) and commercial student accommodation (7\% vs $6 \%$ of men).

\section{Type of education provider}

Share houses were by far the most common first accommodation for students studying in private colleges (35\%) and at university (39\%). A substantially greater proportion of college students lived in a homestay as their first accommodation (14\%) compared with university students (5\%). The same proportion of college students (6\%) and university students (6\%) lived in commercial student housing.

\section{Intended length of stay in Australia}

Share houses were the most common first accommodation for international students regardless of their intended length of stay. This included $36 \%$ of those planning to stay up to 3 months, rising steadily to a peak of $43 \%$ of those planning to stay 13-18 months, and dropping steadily to 34\% of those planning to stay longer than 2 years. University housing was far more common among those planning to stay 3-6 months (27\%) than other periods, possibly including a substantial number of students on exchange from countries such as the USA. 


\section{Whether participants had worked in Australia}

Looking at respondents who had arrived at least three months before the survey, among those who had worked, a greater proportion lived in share houses (39\%) or with friends or family (22\%) in their first accommodation, compared to those who had not worked (32\% and $11 \%$ respectively).

Fewer of the students who worked had lived in university housing (8\%) or commercial student accommodation (5\%) compared with those who had not worked (14\% and 9\% respectively). Indeed, among those living in commercial student accommodation or university housing 50\% of each had worked (compared with 69\% in share houses and $79 \%$ of those living with family or friends). Assuming that many of the students who worked would have been financially compelled to do so, this data suggests that fewer of the students with more limited financial means were obtaining places in student accommodation, and were more commonly in precarious housing situations such as share houses.

\section{Where and when first accommodation was organised}

The majority of respondents organised their first accommodation from their home country before arriving in Australia (71\%). This includes very large proportions of those whose first accommodation was in commercial student accommodation (89\%), university housing (92\%) and with friends and family (92\%).

Even among those whose first accommodation was in a share house, a majority (54\%) organised their accommodation before they came to Australia. However this varied substantially between different nationality groups (Figure 11). Most strikingly, 77\% of Chinese international students organised their share house from China - a far higher proportion than almost every other large nationality group. By contrast, far fewer international students from Nepal (35\%), Colombia (43\%) and India (46\%) organised their first accommodation in a share house from their home country.

Organising accommodation before arrival was similarly common among university and college students, and among men and women.

Figure 11. When respondents organised their first accommodation in a share house, among different nationalities $(n=852)$
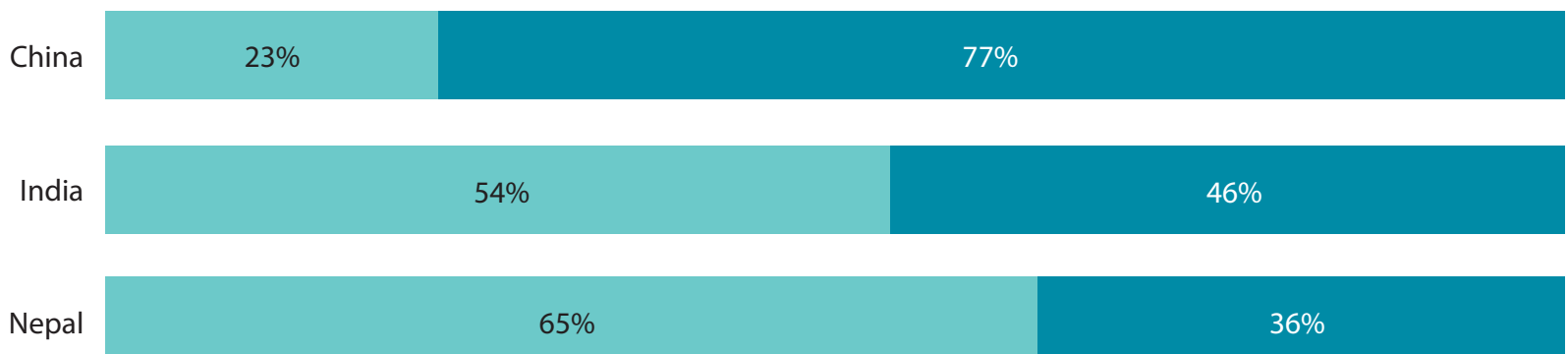

Colombia

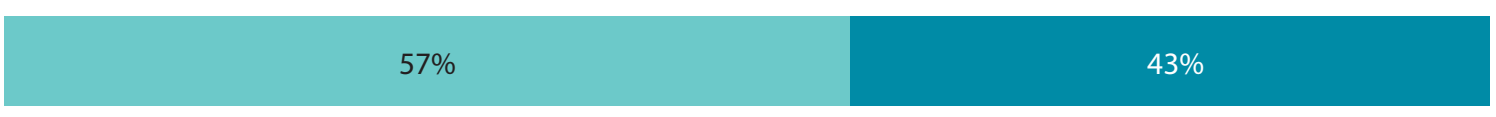

Other 


\section{Why housing organised before coming to Australia}

The most common reasons why students organised their housing pre-arrival were that they felt nervous about not having it organised in advance (51\%) or their parents wanted it organised in advance (41\%) (Figure 12). Over a quarter (27\%) organised their accommodation in advance because they did not know where to stay while looking for housing. This was especially the case among students from China (33\%), Malaysia (37\%) and Colombia (40\%). In the survey, 'I wanted to stay in accommodation that was offered or facilitated by family or friends' was not provided as an option (due to oversight), but was indicated under 'Other' by $2 \%$ of respondents. Given that $18 \%$ of respondents lived with friends or family in their first accommodation, and a third of respondents found share houses from their home country through friends or family (see following section), this proportion would likely have been higher if the option had been explicitly provided to participants as a potential response.

Figure 12. Why respondents organised their accommodation before arriving in Australia $(n=1,691)$

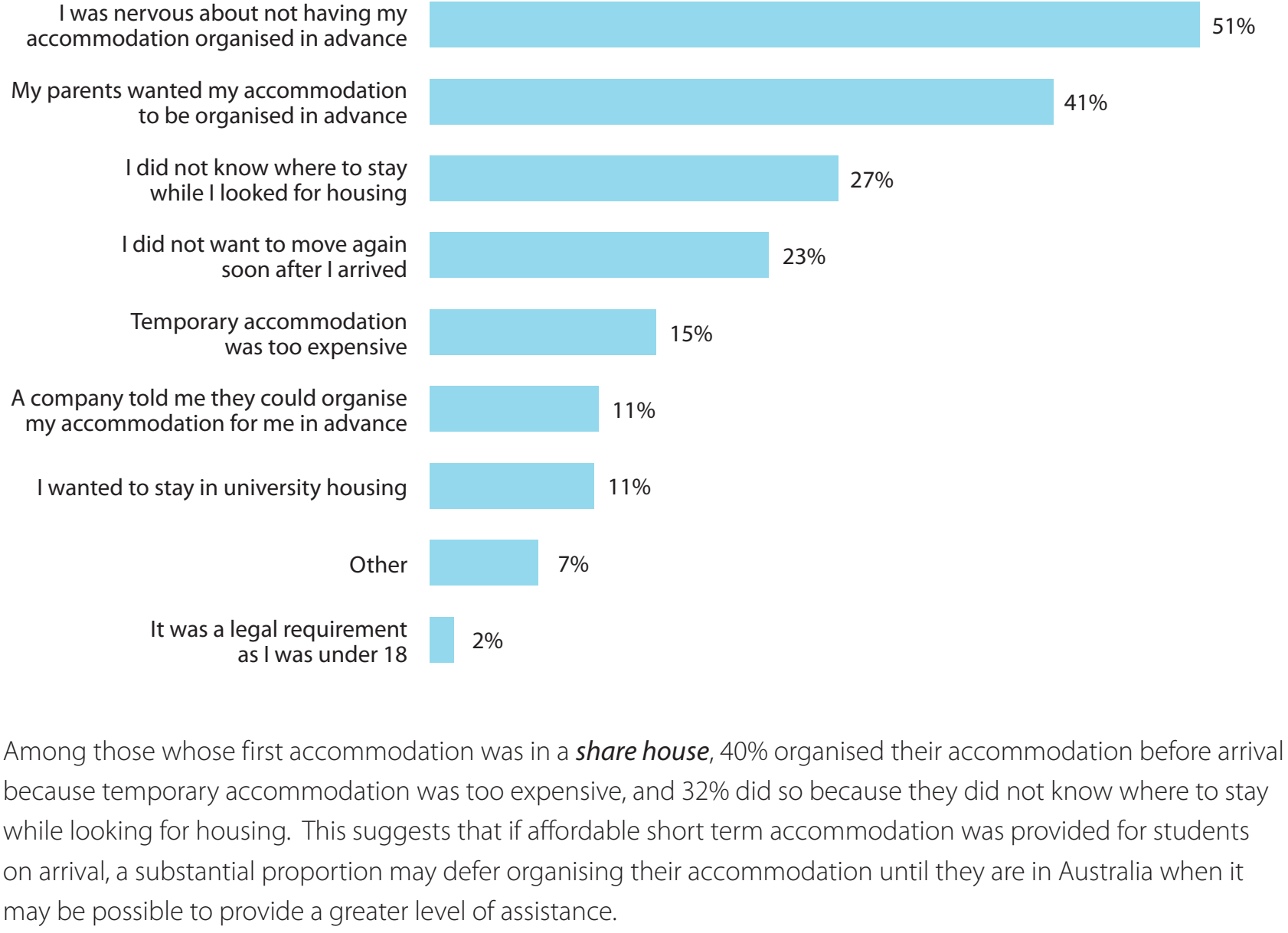

\section{How respondents found their first accommodation in a share house}

Among those whose first accommodation was in a share house, only $2 \%$ received assistance to organise this housing from their university or college.

Over half used an informal online forum - either a peer-to-peer sharing website (28\%) or social media (23\%). A further third (32\%) found their share house through friends or family connections. Websites, social media and family/friends were the top three methods for finding a share house among each of the 10 nationalities with the 
most respondents. ${ }^{10}$

Respondents' methods of finding their first accommodation in a share house varied depending on whether they organised it from their home country or in Australia (54\% did so from their home country, see above). Among those who organised their share house before they came to Australia, 34\% did so through friends and family, 27\% used social media and 21\% used a peer-to-peer sharing website. Among the rest who organised their share house after arrival, a substantially lower proportion (19\%) did so through social media while a higher proportion (36\%) used a peer-to-peer sharing website.

Among the respondents who found their share house through social media, the overwhelming majority of nonChinese international students did so on Facebook (89\%). ${ }^{11}$

Among non-Chinese respondents who found their share house through a peer-to-peer sharing website, the overwhelming majority did so through Flatmates.com.au (48\%) or Gumtree (40\%). Flatmates.com.au was especially popular among students from Brazil (60\%) and Indonesia (70\%), and Gumtree was especially popular among students from Nepal (71\%), India (52\%) and Malaysia (46\%).

Among Chinese students who used social media and peer-to-peer sharing websites to find their first accommodation, the greatest proportion used WeChat (35\%). ${ }^{12}$ One in five (21\%) used Chinese-language website Sydney Today to find their first accommodation. ${ }^{13}$ Smaller proportions of Chinese students used Yeeyi.com (8\%), Gumtree (5\%) and Flatmates.com.au (4\%). The overwhelming majority of Chinese students who used WeChat or Sydney Today to arrange their housing, did so before they arrived in Australia ( $82 \%$ and $67 \%$ respectively).

Four percent of respondents who found their first accommodation in a share house did so through an education agent. $^{14}$

\section{Only 2\% of respondents whose first accommodation was in a share house received assistance from their university or college to organise this housing.}

10 For example, social media was the most common avenue among international students from Vietnam (44\%), Colombia (39\%), Malaysia (36\%), China (34\%) and Brazil (25\%). Peer-to-peer sharing websites were commonly used among international students from China (29\%), Bangladesh (31\%), Malaysia (28\%), India (28\%), Pakistan (26\%) and Brazil (25\%).

11 This may be an over-representation as Facebook was one of the main social media platforms through which the survey was disseminated.

12 Note that this was the primary social media platform used to disseminate the survey to Chinese participants.

13 Sydney Today was provided in open responses, but was not provided as an option to all survey participants. This proportion is therefore likely an underrepresentation of the use of this website by Chinese participants.

14 Overall, education agents found first accommodation for $12 \%$ of respondents. Among these, $51 \%$ were in homestays, $16 \%$ were in commercial student accommodation, $13 \%$ were in university housing and 13\% were in share houses. 


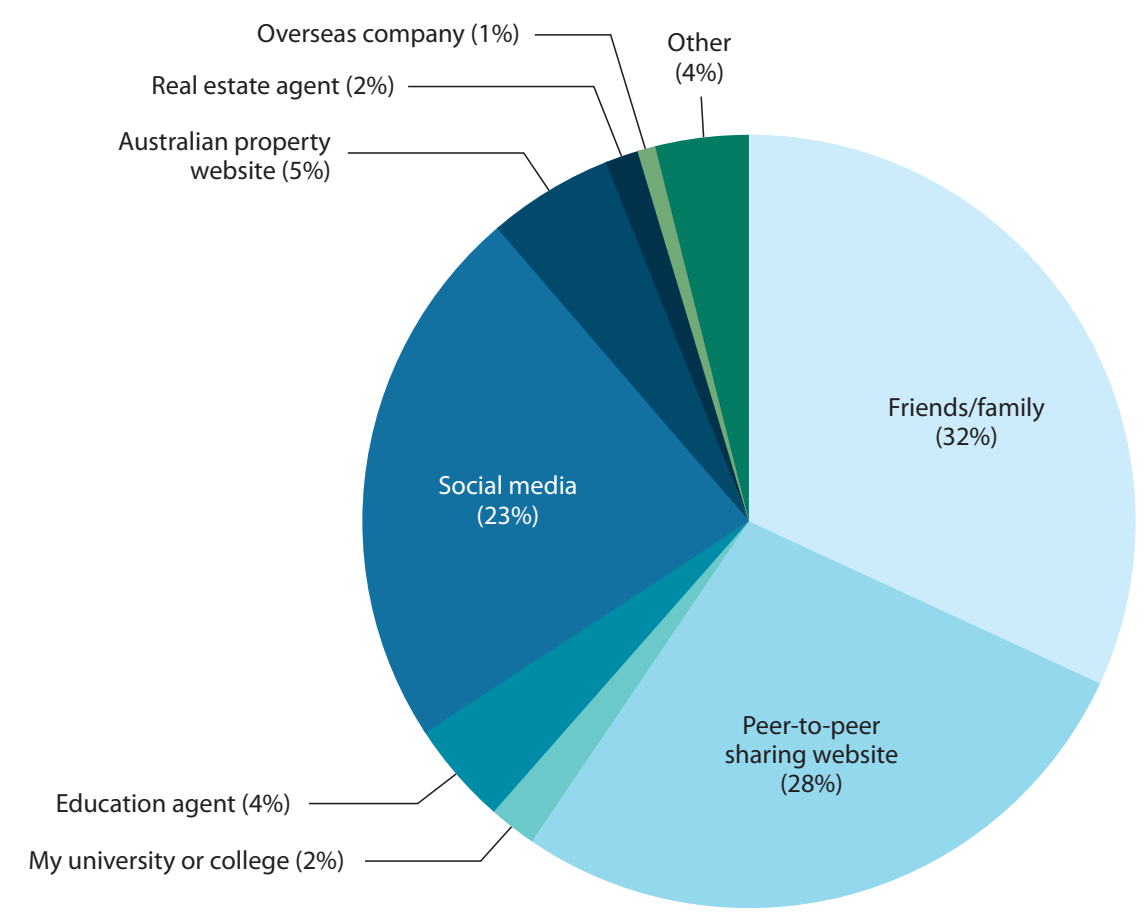

\section{Whether and when respondents moved}

At the time of the survey $61 \%$ of respondents had left their first accommodation and moved to other housing. Among this group, $66 \%$ moved within 6 months of arrival. There were distinct peak periods of moving at 1 month (21\%), 3 months (12\%), 6 months (14\%) and 12 months (12\%). Respondents who had entered agreements to stay in their accommodation for these standard periods of time may have then declined to renew their agreements because they were dissatisfied with the accommodation, or felt confident to seek an alternative form of accommodation. Others may have broken an agreement early due to problems, or may have been evicted or told they could not extend their stay.

The proportion of respondents who left their first accommodation, and the time period after which they moved, varied between types of first accommodation.

- Share house. $66 \%$ had moved to other housing at the time of the survey. Among those who moved, $71 \%$ moved in the first 6 months. The peak times for moving were in the first month (16\%), at 3 months (16\%) and 6 months (17\%).

- Friends or family. $50 \%$ had moved to other housing at the time of the survey. Among those who moved, almost two thirds (63\%) moved in the first 6 months, including 24\% who moved in the first month.

- Commercial student accommodation. 55\% had moved to other housing at the time of the survey. Over half (58\%) did so in the first 6 months. The peak times for moving were in the first month (19\%), at 6 months (14\%) and at 12 months (21\%).

- University housing. $43 \%$ had moved to other housing at the time of the survey. Forty six percent had done so in the first 6 months. The peak times for moving were at 6 months (20\%) and 12 months (23\%).

This data indicates that although a substantial proportion of students had their first accommodation in a less precarious type of housing (such as university housing, commercial student accommodation or living securely with family/friends) many moved to a different type of housing, and often within 6 months of arrival. It is therefore important that housing information and support services are provided not only pre-departure and on arrival, but also at later stages during an international student's stay in Australia. 


\section{Section 5: Experiences of problems in international students' first housing in Australia}

\section{Overview of housing problems encountered by international students}

The No Place Like Home report, released by UNSW Human Rights Clinic in 2019, identified a range of housingrelated problems that international students commonly encounter in NSW. ${ }^{15} \mathrm{It}$ found that many students typically encounter multiple housing problems simultaneously.

Service providers often see international students who report that their landlords did not return some or all of the student's bond. Although bond receipts are mandatory under state tenancy laws, international students commonly do not receive a receipt for bond or other money paid and have no proof of payment. In NSW, NSW Fair Trading provides an online service for the payment, management, and return of bonds, which means that the bond is paid directly to the Rental Bond Board rather than the landlord. However, many landlords and agents do not offer this option to international students. International students in share houses who do not have a written agreement with the head tenant are not protected by the state tenancy law, the Residential Tenancies Act 2010 (NSW) ('RTA'). International students in share houses commonly do not have a written agreement and therefore lack legal rights. In NSW, these students are the most vulnerable to landlords improperly keeping their bond, as are students in accommodation classified as a boarding house for which a bond is not required to be lodged.

In addition to creating emotional distress, improper withholding of bonds from international students can compel them to remain in poor or dangerous housing, and financially prevent them from seeking alternative accommodation. Landlords and agents commonly require international students to pay a lot of money upfront which may include a bond that is more than four weeks of rent or several weeks of advance rent (both prohibited under the $R T A$ ).

Unscrupulous landlords and agents are able to perpetrate scams and deceive international students by taking advantage of cultural differences and international students' lack of awareness of their rights or standard Australian housing practices. International students easily fall for scams that charge upfront for rental properties that do not exist at all. International students may pay for property and later find the property is different to what was described, and/or be told that the accommodation is 'not ready' and be required to pay extra to stay somewhere else. They may confront further obstacles where landlords fail to provide their correct contact details. In some cases, the landlord liquidates and transfers its assets to a new company (phoenixing) so the international student cannot recover money they paid upfront, or their bond at the end of a lease. International students also encounter landlords who suddenly increase rent in the middle of a rental period and impose other excessive costs, including for repairs and cleaning fees. All of these deceptive practices have significant financial consequences that exacerbate the already considerable financial burden that international students face in Sydney.

Some international students are unfairly evicted with little or no notice, often when the landlord wants the room for a new higher-paying tenant. Landlords also undertake 'informal evictions' by harassing the student and/ or making the accommodation intolerable. Emergency accommodation is generally unavailable to international students who are suddenly evicted.

International students may live in overcrowded housing - either knowingly in order to make accommodation affordable, or through deception where the landlord moves in other people without their consent and they do not necessarily receive the financial benefit of overcrowding because each tenant is overcharged. International students may also experience accommodation that is unsafe or not fit to live in, or in which they feel unsafe. In some circumstances, when international students report problems the landlord will not make repairs.

15 'UNSW Human Rights Clinic, No Place Like Home: Addressing Exploitation of International Students in Sydney's Housing Market (2019). 
International students confront bullying behaviour and intimidation or harassment by landlords or tenants. Many are fearful of addressing this behaviour and other issues with their accommodation because they lack alternative affordable accommodation options, or because landlords threaten to report the student to immigration authorities if they take action. Some encounter sexual harassment by landlords or tenants.

\section{Structure of questions on housing problems in the survey}

Survey participants were asked if they had experienced any of a defined set of problems in their first accommodation and/or subsequent accommodation, based in part on the problems identified in bold text in the previous section. Across all types of accommodation, over half (52\%) of respondents indicated that they had experienced at least one of these problems in either their first or later accommodation or both. Though respondents likely experienced these problems with varying levels of severity, it is clear that a substantial proportion of respondents experienced deceptive and exploitative conduct, poor living conditions and harassment.

This section reports on the proportions of participants who experienced a problem in their first housing, including for different types of first housing and how they found that housing. These findings need to be interpreted with care: the proportions of students who reported experiencing problems in their first accommodation are likely the tip of the iceberg.

The survey does not provide data on the type of housing in which participants experienced problems beyond their first housing, and it does not provide data on the number of housing situations in which problems arose. Participants were asked about problems in first or later housing, however they were only asked to identify the type of housing for their first housing in Australia. As a result:

- For participants'first housing, the data enables comparisons to be made between experiences of problems in different housing types.

- The data does not allow for comparisons of problems between housing types for subsequent accommodation.

- It is, therefore, not possible to determine the prevalence of problems in any particular housing type across all of the places in which participants lived.

Therefore, findings on proportions of participants who experienced a problem in their first housing do not reflect the number of instances in which participants experienced problems in any particular type of housing, including in subsequent housing. Participants may have experienced problems multiple times in the multiple accommodations. Others may have had problem-free first housing but moved on to one or more problematic housing situations. Indeed, $61 \%$ of participants moved from first housing to other housing (see above) and, as discussed in the next section, each problem was similarly common in first housing and subsequent housing.

\section{Experiences of problems for share houses compared with other types of first accommodation}

Almost all problems in first accommodation were experienced by a greater proportion of respondents whose first accommodation was in a boarding house. However, the number of respondents in this category was small (55 individuals) compared with other types of accommodation.

Other than those in boarding houses, almost all problems were experienced by more participants in share houses than any other type of housing. Figures 14-17 below reveal that every problem was more commonly experienced by international students in share houses than other housing types. 
Figure 14. Proportion of respondents who reported problems in first accommodation, comparing share house and all others (share house $n=850$; non-share house $n=1528$ )

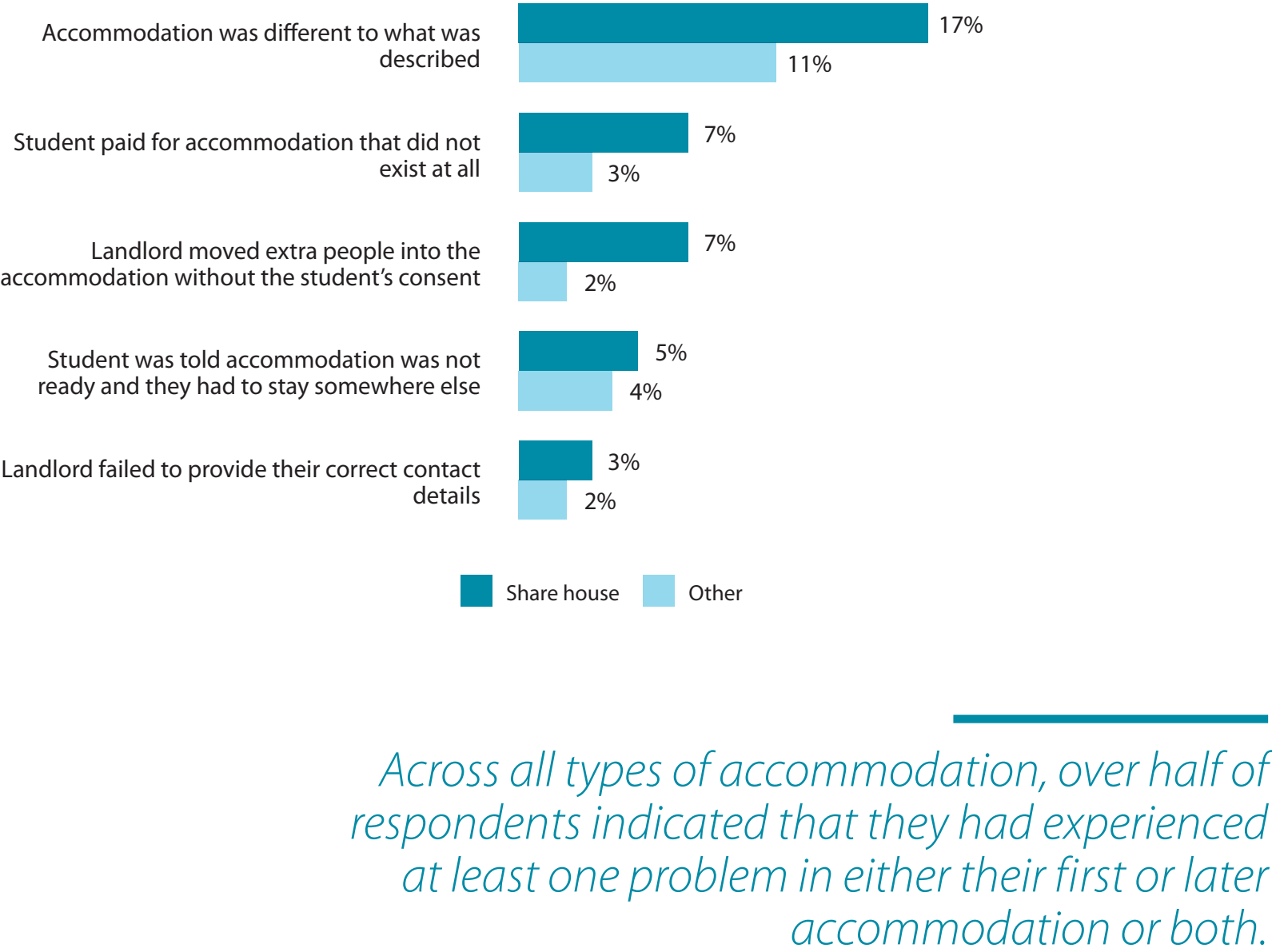

Figure 15. Proportion of respondents who reported financial and other exploitative practices in first accommodation, comparing share house and all others (share house $n=850$; non-share house $n=1528$ )

Student did not receive a receipt for money paid in cash

Landlord required the student to pay a lot of money up front

Landlord would not return some or all of the student's bond

Landlord suddenly increased the rent in the middle of the rental period

Student was unfairly evicted

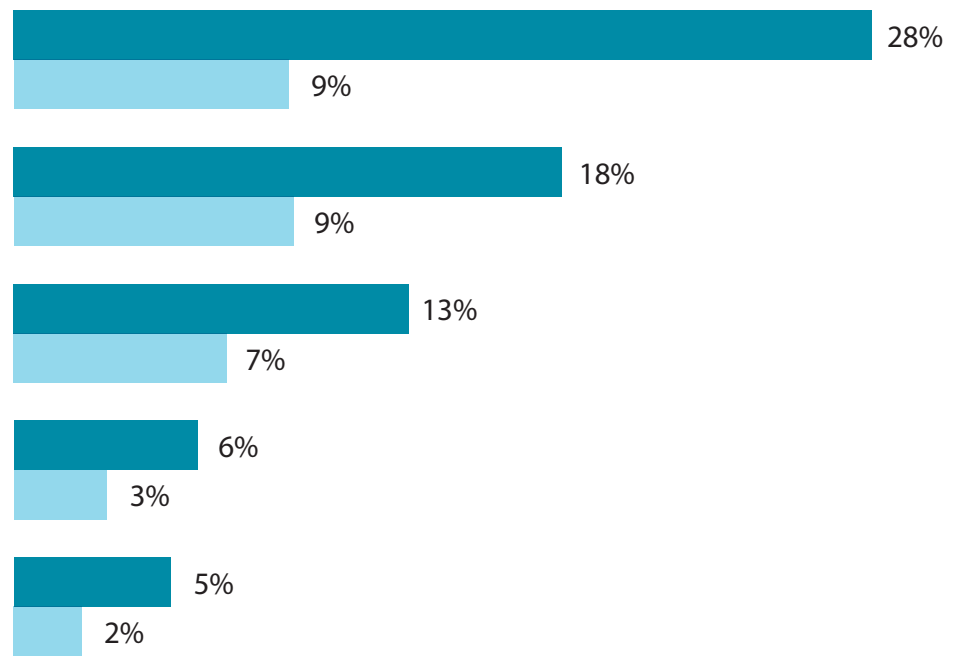

Share house Other 
Figure 16. Proportion of respondents who reported poor living conditions in first accommodation, comparing share house and all others (share house $n=850$; non-share house $n=1528$ )

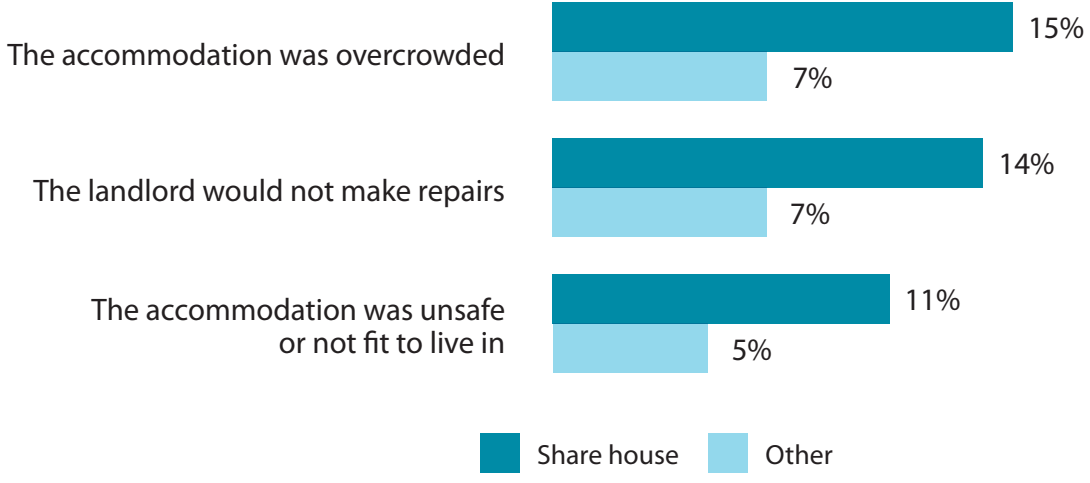

Figure 17. Proportion of respondents who reported intimidation or harassment in first accommodation, comparing share house and all others (share house $n=850$; non-share house $n=1528$ )

Intimidation or harassment by landlord or tenant

Sexual harassment by landlord or tenant

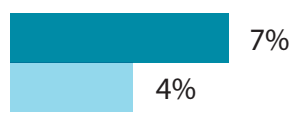

$1 \%$

$1 \%$

As discussed in the previous section, the proportion of respondents who experienced each problem in a share house during their stay in Australia is likely to be substantially greater than these figures, which relate only to respondents' experience in a share house as their first accommodation. ${ }^{16}$ They do not reflect problems encountered by respondents in later share houses, or by other respondents who subsequently moved from more secure types of housing to one or more share houses where they experienced more problems.

Table 5 (Appendix) sets out prevalence of problems in first accommodation across each housing type. It reveals:

- Most problems were experienced by a smaller proportion of respondents in university housing than other housing types.

- Many problems were experienced by a substantial proportion of international students whose first accommodation was in a homestay, including overcrowding (8\%), accommodation that was unsafe or not fit to live in (8\%), and intimidation or harassment (7\%).

- Many problems were experienced by a substantial proportion of international students whose first accommodation was in commercial student accommodation. Among these, one in twenty (5\%) paid for accommodation that did not exist at all and $7 \%$ were told their accommodation was not ready and they had to stay somewhere else (higher than for any other accommodation type). One in ten (10\%) described the accommodation as overcrowded and 6\% described it as unsafe or not fit to live in.

16 The data does not reflect the overall prevalence of problems experienced by international students in share houses during their time in Australia. It remains useful, however, for identifying factors that coincide with problems in share houses, or comparing the incidence of problems in different types of first accommodation. 
- Sexual harassment was reported by participants in all types of first accommodation (besides boarding houses, which had a very small number of respondents). Intimidation and other forms of harassment were also reported in all accommodation types, though this was most common in share houses (7\%), homestays (7\%) and boarding houses (6\%). Across all accommodation types, sexual harassment may have been underreported among participants who either did not recognise particular conduct as sexual harassment, or were uncomfortable acknowledging sexual harassment even in an anonymous survey. ${ }^{17}$

\section{Experiences of problems in first housing found through peer-to-peer sharing websites, social media and other channels}

Among those whose first accommodation was in a share house, a greater proportion of students reported at least one problem when they had found that share house directly through social media (63\%) or a peer-to-peer sharing website (63\%) than those who found it through other methods such as an Australian property website, friends/family, or their education provider (labelled'mainstream methods' in Figure 18) (50\%). For example, among respondents who found their share house through social media or a peer-to-peer sharing website, a substantially greater proportion was made to pay a lot of money upfront, or experienced overcrowding, withholding of bond, accommodation that was unsafe or not fit to live in, intimidation or harassment or unfair eviction.

Figure 18. Proportion of respondents who reported problems in first accommodation in share houses, comparing methods of finding the share house ( $n=850)$

The landlord made me pay a lot of money up front

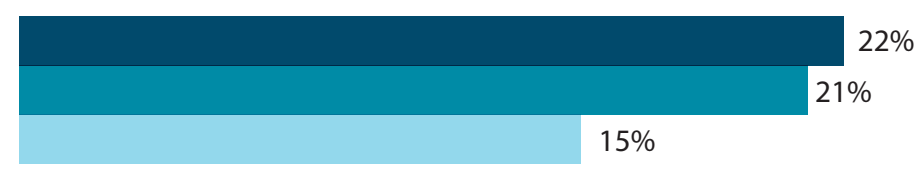

Overcrowding

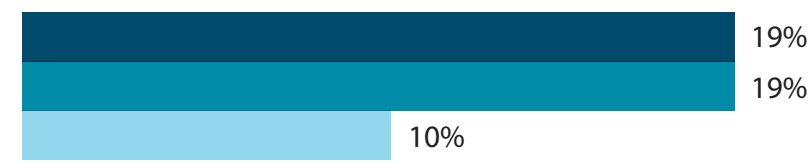

Landlord refused to return bond

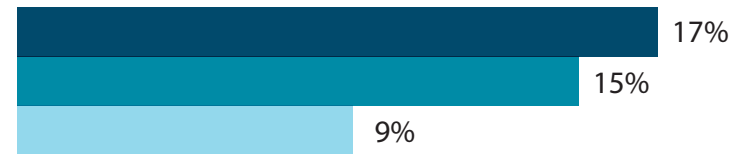

$9 \%$

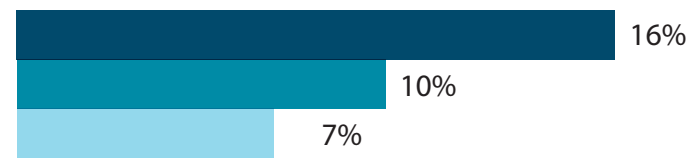

The accommodation was unsafe or not fit to live in

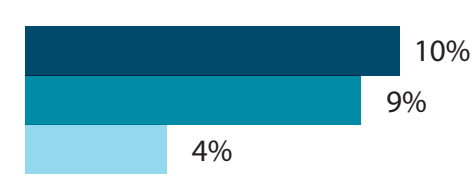

Intimidation or harassment

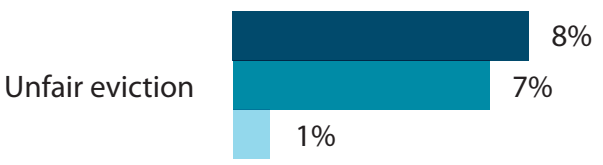

$1 \%$ 
Some problems were especially common among international students who found their accommodation through Flatmates.com.au and Gumtree, as indicated in Table 3 below. Of particular note, 11\% of those who found their accommodation on Gumtree indicated that they paid for accommodation that did not exist.

Table 3. Proportion of respondents reporting problems, among those who used peer-to-peer sharing websites Flatmates.com.au or Gumtree ( $n=223$ )

\begin{tabular}{|c|c|c|}
\hline & \\
\hline & Flatmates.com.au & Gumtree \\
\hline I did not get a receipt for money I paid in cash & $30 \%$ & $28 \%$ \\
\hline The accommodation was different to what was described & $12 \%$ & $15 \%$ \\
\hline The landlord made me pay a lot of money upfront & $23 \%$ & $18 \%$ \\
\hline The accommodation was overcrowded & $16 \%$ & $18 \%$ \\
\hline The landlord would not make repairs & $10 \%$ & $16 \%$ \\
\hline The landlord would not give some or all of my bond back & $17 \%$ & $12 \%$ \\
\hline The accommodation was unsafe or not fit to live in & $7 \%$ & $10 \%$ \\
\hline I was intimidated or harassed in other ways by my landlord or other tenants & $11 \%$ & $11 \%$ \\
\hline I paid for accommodation that did not exist & $4 \%$ & $11 \%$ \\
\hline The landlord suddenly increased the rent in the middle of the rental period & $3 \%$ & $5 \%$ \\
\hline I was told the accommodation was not ready and I had to stay somewhere else & $5 \%$ & $9 \%$ \\
\hline The landlord moved extra people into my accommodation and I had not agreed to this & $8 \%$ & $6 \%$ \\
\hline I was unfairly evicted & $11 \%$ & $5 \%$ \\
\hline The landlord did not give me their correct contact information & $4 \%$ & $2 \%$ \\
\hline I was sexually harassed by my landlord or other tenants & $3 \%$ & $1 \%$ \\
\hline
\end{tabular}

Across accommodation types generally, Figure 19 reveals that organising accommodation through 'a company that organises student accommodation' or an education agent was also associated with higher rates of certain problems than organising accommodation through other methods such as an Australian property website, friends/ family or their education provider (labelled 'mainstream methods' in Figure 19). 
The accommodation was overcrowded

The accommodation was unsafe or not fit to live in

I was intimidated or harassed by my landlord or other tenants

A company that organises accommodation
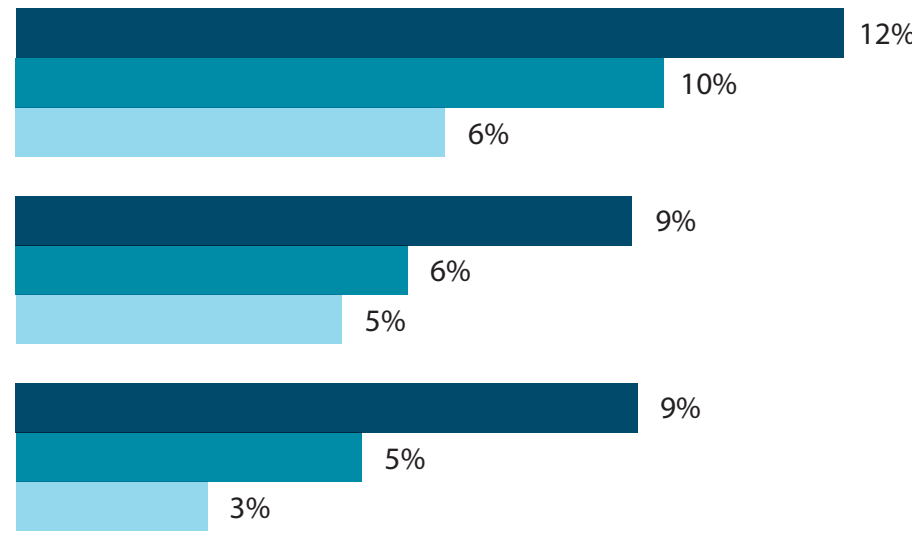

$3 \%$

Mainstream methods

Sexual harassment, intimidation and other forms of harassment were reported by participants in all types of accommodation

\section{Prevalence of problems in share houses organised before coming to Australia and housing organised after arrival}

As discussed in Section 4, many participants organised their first housing in a share house from their home country (54\%) compared with 46\% who organised it after arrival in Australia. One would expect that being present in Australia when arranging housing enables students to better avoid problems, and that problems in international students'first housing would be more common among those who organised their housing before coming to Australia than those who organised it after arrival. For example, it might be assumed that students onshore could avoid poorer quality housing or deceptive conduct and scams since they have better access to information or advice (including from friends) or the opportunity to inspect the property and meet prospective housemates. However, as indicated in Figure 20 below, contrary to these assumptions, the incidence of problems reported by respondents in share houses was generally just as high for those who organised their first housing while present in Australia, as for those who organised it from home. This included poor quality housing and deceptive practices. For example, comparing those who organised their first accommodation in a share house before coming to Australia with those who organised it after arrival, similar proportions reported overcrowding (15\% of each), housing that was unsafe or not fit to live in ( $8 \%$ vs 13\%), housing that was different to what was described (19\% vs 15\%) and even paying for accommodation that did not exist (5\% vs $8 \%$ ). 
Figure 20. Proportion of respondents who reported problems where their first housing was a share house, comparing whether they organised the share house pre-arrival or in Australia

I did not get a receipt for money I paid in cash

The accommodation was different to what was described

The landlord made me pay a lot of money upfront

The accommodation was overcrowded

The landlord would not make repairs

The landlord would not give some or all of my bond back

The accommodation was unsafe or not fit to live in

I was intimidated or harassed in other ways by my landlord or other tenants

I paid for accommodation that did not exist

The landlord suddenly increased the rent in the middle of the rental period

I was told the accommodation was not ready and I had to stay somewhere else

The landlord moved extra people into my accommodation and I had not agreed to this

I was unfairly evicted

The landlord did not give me their correct contact information

I was on the lease and became responsible for other subtenants

I was sexually harassed by my landlord or other tenants

Other

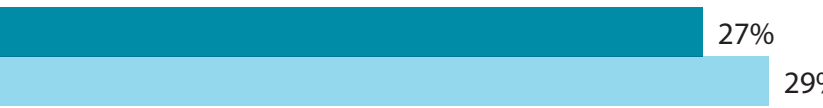

$29 \%$
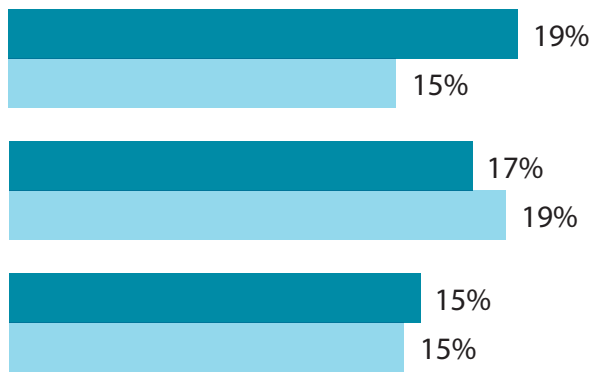

$15 \%$

$15 \%$

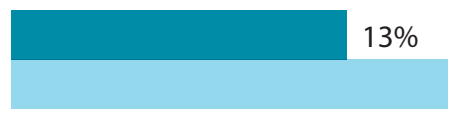

$16 \%$
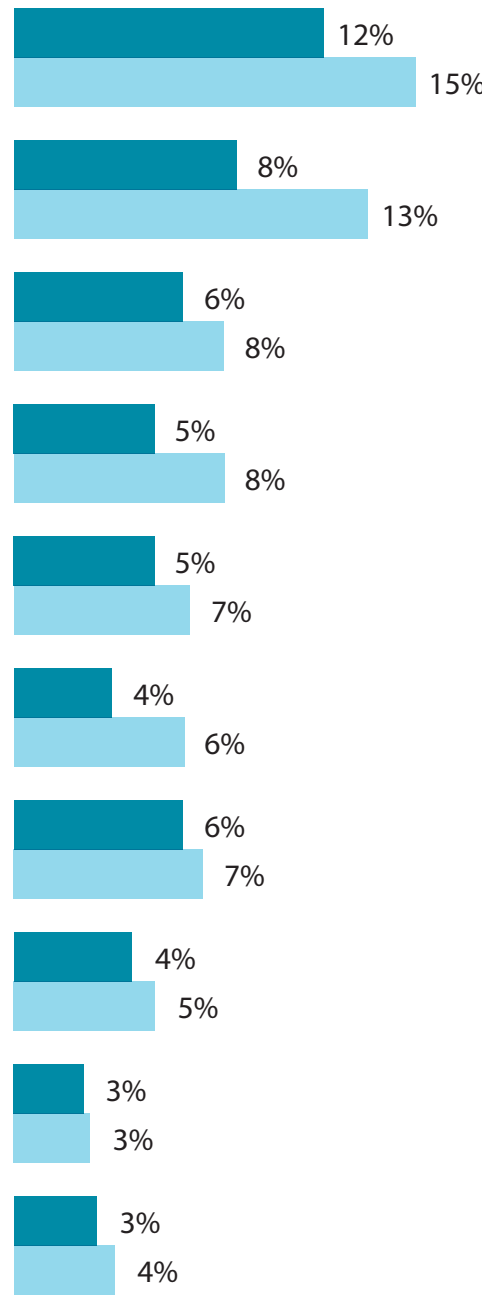

$1 \%$

$2 \%$

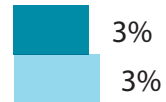

Organised pre-arrival $(n=457)$

Organised in Australia $(n=393)$ 
It is not obvious why this is the case, although there are a number of potential explanations that would benefit from further consideration in future studies. One possible explanation is that respondents who organised their share house in Australia used different channels to find the share house compared with those who organised their share house from home. However, as indicated in Table 4 below, the incidence of problems in share houses was broadly similar among those who organised their share house in Australia and those who organised it from home, regardless of the channel used. (Table 4 shows this for share houses found by informal sharing websites, social media and friends and family.)

Another potential contributing factor is that certain nationalities were more likely to organise their first accommodation in a share house after arriving in Australia, and those nationalities experienced some problems in share houses more frequently than others. For instance, students from India, Nepal, Brazil and Colombia were more likely than other national groupings to organise their housing onshore (see Section 4 above). Students of these nationalities experienced certain problems with somewhat higher frequency compared with other nationalities, though this was not the case for all problems, or for all of these nationalities across problems (see problems reported by participants, according to nationality in Table 6, Appendix A).

\section{Surprisingly, the incidence of problems reported by respondents in share houses was generally just as bad for those who organised their first housing while present in Australia, as for those who organised it from their home country.}

Finally, it may be the case that problems in share houses are the result of factors that are not related to when and how they are organised. In particular, low-cost share houses may more frequently be of poor quality with landlords or head tenants who engage in exploitative practices, but international students cannot avoid these because they cannot afford higher rents in better housing. In terms of deceptive practices, some students organising a share house onshore may not have better opportunities to inspect a property or make demands than those who organise housing offshore. The landlord may require immediate payment of money upfront and students may be unwilling to risk losing an affordable bed in a competitive and expensive market. Students may also lack confidence to resist an insistent landlord, particularly if the connection to the landlord is through family or friends or within their community (note the high prevalence of problems in share houses organised onshore through family and friends in Table 4 above, including paying for property that does not exist).

It is also possible that some students who organised their share house from home were willing to pay a premium for their first housing for a short time and therefore secured better quality share houses, counterbalancing any advantages of students onshore (the survey did not ask respondents how much they paid in rent in their first housing). Finally, it may be the case that rather than providing information that enables students to avoid problems, friends and contacts in Australia may calibrate international students' expectations of living conditions given the low rent they can afford. In doing so they may encourage students to accept poor conditions without further interrogation on the basis that international students should not realistically expect to find a better alternative near campus at that price. Further research is required to explore and test each of these hypotheses. 
Table 4. Problems reported by respondents who used various channels to organise their first accommodation in a share house $(n=701)$

\begin{tabular}{|c|c|c|c|c|c|c|}
\hline & \multicolumn{2}{|c|}{$\begin{array}{l}\text { Peer-to-peer sharing } \\
\text { website }\end{array}$} & \multicolumn{2}{|c|}{ Social media } & \multicolumn{2}{|c|}{ Friends and family } \\
\hline & Offshore & Onshore & Offshore & Onshore & Offshore & Onshore \\
\hline $\begin{array}{l}\text { I did not get a receipt for money I paid in } \\
\text { cash }\end{array}$ & $22 \%$ & $35 \%$ & $33 \%$ & $36 \%$ & $26 \%$ & $22 \%$ \\
\hline $\begin{array}{l}\text { The accommodation was different to what } \\
\text { was described }\end{array}$ & $17 \%$ & $15 \%$ & $18 \%$ & $25 \%$ & $14 \%$ & $10 \%$ \\
\hline $\begin{array}{l}\text { The landlord made me pay a lot of money } \\
\text { upfront }\end{array}$ & $19 \%$ & $22 \%$ & $19 \%$ & $26 \%$ & $14 \%$ & $14 \%$ \\
\hline The accommodation was overcrowded & $20 \%$ & $18 \%$ & $20 \%$ & $18 \%$ & $10 \%$ & $11 \%$ \\
\hline The landlord would not make repairs & $13 \%$ & $12 \%$ & $13 \%$ & $22 \%$ & $14 \%$ & $15 \%$ \\
\hline $\begin{array}{l}\text { The landlord would not give some or all of } \\
\text { my bond back }\end{array}$ & $14 \%$ & $15 \%$ & $15 \%$ & $21 \%$ & $8 \%$ & $11 \%$ \\
\hline $\begin{array}{l}\text { The accommodation was unsafe or not fit to } \\
\text { live in }\end{array}$ & $6 \%$ & $13 \%$ & $12 \%$ & $23 \%$ & $3 \%$ & $7 \%$ \\
\hline $\begin{array}{l}\text { I was intimidated or harassed in other ways } \\
\text { by my landlord or other tenants }\end{array}$ & $11 \%$ & $9 \%$ & $8 \%$ & $15 \%$ & $3 \%$ & $4 \%$ \\
\hline I paid for accommodation that did not exist & $7 \%$ & $6 \%$ & $4 \%$ & $7 \%$ & $3 \%$ & $15 \%$ \\
\hline $\begin{array}{l}\text { The landlord suddenly increased the rent in } \\
\text { the middle of the rental period }\end{array}$ & $2 \%$ & $5 \%$ & $6 \%$ & $8 \%$ & $6 \%$ & $6 \%$ \\
\hline $\begin{array}{l}\text { I was told the accommodation was not ready } \\
\text { and I had to stay somewhere else }\end{array}$ & $5 \%$ & $7 \%$ & $3 \%$ & $8 \%$ & $2 \%$ & $4 \%$ \\
\hline $\begin{array}{l}\text { The landlord moved extra people into my } \\
\text { accommodation and I had not agreed to this }\end{array}$ & $5 \%$ & $8 \%$ & $6 \%$ & $6 \%$ & $6 \%$ & $4 \%$ \\
\hline I was unfairly evicted & $7 \%$ & $6 \%$ & $8 \%$ & $10 \%$ & $1 \%$ & $3 \%$ \\
\hline $\begin{array}{l}\text { The landlord did not give me their correct } \\
\text { contact information }\end{array}$ & $2 \%$ & $2 \%$ & $3 \%$ & $0 \%$ & $1 \%$ & $4 \%$ \\
\hline $\begin{array}{l}\text { I was on the lease and became responsible } \\
\text { for other subtenants }\end{array}$ & $3 \%$ & $3 \%$ & $4 \%$ & $6 \%$ & $1 \%$ & $4 \%$ \\
\hline $\begin{array}{l}\text { I was sexually harassed by my landlord or } \\
\text { other tenants }\end{array}$ & $1 \%$ & $1 \%$ & $1 \%$ & $4 \%$ & $1 \%$ & $0 \%$ \\
\hline Other & $2 \%$ & $5 \%$ & $3 \%$ & $0 \%$ & $3 \%$ & $3 \%$ \\
\hline None of the above & $44 \%$ & $33 \%$ & $40 \%$ & $33 \%$ & $53 \%$ & $50 \%$ \\
\hline
\end{tabular}




\section{Section 6: Experiences of problems in subsequent accommodation and among different demographic cohorts}

This section turns to findings on problems experienced by participants across both first and subsequent accommodation in Australia.

\section{Comparing the experience of problems in first and subsequent accommodation}

It might be expected that fewer participants would experience problems in subsequent housing, because they would learn from experiences in first housing and/or be better equipped to obtain information and assistance to avoid problems. This was not the case.

The proportion of respondents who reported problems for any subsequent accommodation was the same or greater for virtually every type of problem. ${ }^{18}$ The only problem reported by more respondents in relation to first accommodation than subsequent accommodation was that housing was 'different to what was described'.

One partial explanation for this is that some respondents were reporting on the incidence of problems across more than one subsequent housing situation, unlike first accommodation in which each respondent was reporting on a single housing situation. ${ }^{19}$ However, it is also possible that respondents who had more than one subsequent housing experienced problems in each of those situations.

The similar incidence of problems across first and later housing may also be explained by the fact that a large proportion of respondents had moved out of certain forms of more secure housing at the time of the survey, e.g. those whose first accommodation was in university housing (43\%), with friends or family (55\%) or commercial student accommodation (55\%). Though respondents were not asked to specify the category of their subsequent accommodation, most of these students would likely have moved from this secure accommodation in which they experienced fewer problems into more precarious accommodation such as share houses, in which they experienced more problems.

The similar prevalence of problems across first and subsequent accommodation may also be explained by students moving from one form of precarious housing to another. Some may have experienced different problems in each housing. Others may have experienced the same problem more than once. Some problems may be difficult for anyone to anticipate (e.g. landlord failing to make repairs). Others may be difficult for international students to avoid based on their limited financial means and access to the rental market (e.g. overcrowding). For others, international students may have continued to lack the knowledge to identify warning signs regardless of their earlier experience (e.g. failure to obtain a receipt for money paid in cash), and likely had no greater access to assistance from their education provider or elsewhere to identify better quality share houses.

\section{It might be expected that fewer participants would experience problems in subsequent housing than first housing. This was not the case.}

18 Second accommodation $n$ was based on the number of respondents who indicated that they moved from their first accommodation ( $\mathrm{n}=1,450$ ).

19 The sample size of subsequent accommodation situations is unknown but is almost certainly larger than the number of individuals who reported moving $(n=1,450)$ because we do not know how many times those individuals moved. 
I did not get a receipt for money I paid in cash

The accommodation was different to what was described

The landlord made me pay a lot of money upfront

The accommodation was overcrowded

The landlord would not make repairs

The landlord would not give some or all of my bond back

The accommodation was unsafe or not fit to live in

I was intimidated or harassed in other ways by my landlord or other tenants

I paid for accommodation that did not exist

The landlord suddenly increased the rent in the middle of the rental period

I was told the accommodation was not ready and I had to stay somewhere else

The landlord moved extra people into my accommodation and I had not agreed to this

I was unfairly evicted

The landlord did not give me their correct contact information

I was on the lease and became responsible for other subtenants I was sexually harassed by my landlord
or other tenants

Other

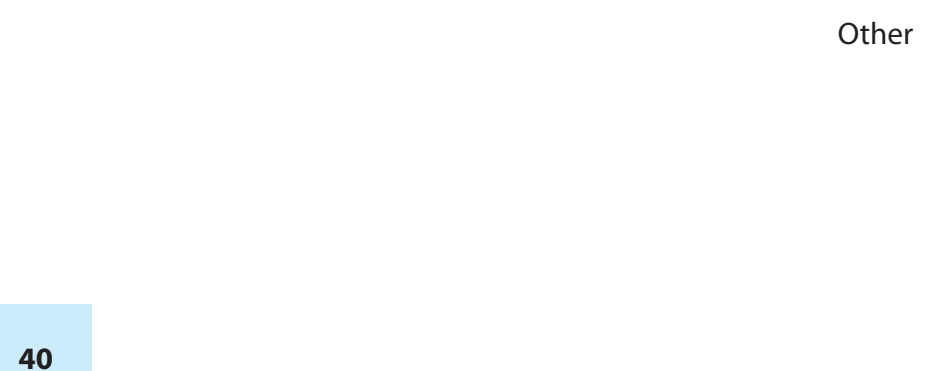




\section{Prevalence of problems among different demographic cohorts}

Examining the prevalence of problems across first and subsequent accommodation combined, certain cohorts of international students experienced problems with greater frequency.

\section{Nationality}

The prevalence of reported problems varied by nationality, as indicated in Table 6 (Appendix A). Paying for nonexistent accommodation was reported by an especially large proportion of respondents from Nepal (20\%), Vietnam (17\%), Bangladesh (13\%) and India (12\%). Overcrowding was reported by particularly high proportions of students from China (21\%), Brazil (18\%), Vietnam (18\%), India (16\%) and Nepal (15\%). One in ten Brazilians and Colombians $(11 \%)$ reported that their landlord moved more people into the apartment without their agreement.

Sexual harassment was experienced by respondents in almost all of the top 15 nationalities. A particularly high proportion of students experienced other forms of intimidation or harassment by their landlord or other tenants among students from Brazil (14\%), Philippines (13\%), Bangladesh (13\%), India (10\%) and Malaysia (10\%).

\section{Gender}

Most problems were reported by similar proportions of men and women. Notably, 28 women (2\%) and 19 men (2\%) reported experiencing sexual harassment in their accommodation, and similar proportions of women and men reported other forms of intimidation or harassment ( $9 \%$ and $8 \%$ respectively).

\section{English language}

There is a widely held assumption that international students are more vulnerable to deceptive or exploitative conduct in accommodation because they have poor English language skills. However, among survey respondents, most problems were reported by similar proportions of those with self-reported good English language ability and those with fair or poor English. One possible explanation for this may be that many of those with selfreported good English include students from India, Nepal and Bangladesh, who are vulnerable to exploitation or poor living conditions for other reasons. One notable exception to the similarity between the cohorts was overcrowding, which was reported by $14 \%$ of those with good or very good English, and $21 \%$ of those with poor or fair English (excluding respondents who stayed in university housing). Those with poor English would likely be underrepresented among those who experienced problems. Other than speakers of Mandarin, Portugese and Spanish for whom the survey was available in translation, those with poor English would have been unlikely to have completed the survey in English.

\section{Almost all problems were experienced by a similar proportion of college students and university students}

\section{Type of education provider}

Almost all problems were experienced by a similar proportion of college students and university students (excluding respondents who stayed in university accommodation). These findings dispel a common misperception that university students are less vulnerable than English language or vocational students when it comes to exploitation in accommodation. 


\section{Section 7: Discussion and recommendations}

\section{Poor conditions and exploitative practices were substantially more common in share houses - by far the most prevalent first accommodation for international students}

Most of the information international students receive on housing before they come to Australia relates to housing on campus and commercial student housing. However, only $18 \%$ of survey respondents lived in these types of housing on arrival. Far more had their first housing in a share house than any other type of housing (36\% of all respondents). Share houses were by far the most common form of first accommodation for both men and women, as well as for students at private colleges and universities. This was also the case regardless of respondents' intended length of stay in Australia. Many more respondents would also have likely lived in a share house in their second or later accommodation (43\% of those who lived on campus and $55 \%$ of those who lived in commercial student housing had moved to other housing at the time of the survey).

Half of all respondents indicated that they had experienced one or more of the enumerated problems in their housing in Australia. However, almost all problems were more commonly experienced by international students whose first accommodation was in a boarding house or share house than any other housing type. This included overcrowding, accommodation that was unsafe or not fit to live in, payment for accommodation that did not exist, intimidation or harassment by a landlord or another tenant, a landlord moving extra people into the accommodation without the student's consent, a landlord suddenly increasing the rent in the middle of a rental period and unfair eviction.

It is clear from this data that the primary focus of housing-related information, advice and services for international students, and enforcement efforts by government, should be on share houses and boarding houses. It is also clear that current efforts are not effective in preventing poor conditions and exploitative conduct, or enabling international students to avoid falling victim to problems. Substantial resources, and new approaches to services, regulation and enforcement, need to be urgently developed and deployed.

\section{There is a pressing need for improved information and expanded housing services, pre-departure and in Australia}

There is a general recognition within the international education sector that international students need far better housing information pre-departure since most arrange their first accommodation before arriving in Australia. This is borne out by our findings: well over half of international students organised their first accommodation from home. Many universities have sought to provide students with pre-departure information on university housing and/or commercial student accommodation, and indeed the overwhelming majority of students whose first accommodation was in commercial student housing or university housing arranged these before arriving in Australia. However, the findings also underscore the importance of providing quality pre-departure information on share houses, as $54 \%$ of international students who first lived in a share house organised it before they came to Australia (including three quarters of Chinese students). This should include engaging with students to assist them to identify red flags in advertisements on social media or peer-to-peer sharing sites, and guidance to identify adequate share house accommodation.

There is less recognition of the level of assistance and information students need when securing accommodation when they are onshore. The findings of this survey indicate that presence in Australia does not reduce international students' vulnerability to exploitative conduct in the marginal rental market. Almost half of students whose first accommodation was in a share house arranged it after arrival, including substantially greater proportions of some nationalities, e.g. Indian and Nepalese students. This survey reveals that the prevalence of most problems, including deception and poor housing conditions, did not diminish among those who organised their accommodation after arrival. In addition, almost two-thirds of students moved to other housing during their time 
in Australia, including from more secure housing to share houses or between share houses. The overall incidence of problems was similar between international students'first accommodation and subsequent accommodation. The proportion of participants who indicated that they experienced each problem in a share house in their first accommodation is therefore likely the tip of the iceberg. ${ }^{20}$

\section{Exploitation can be reduced through increased accountability and improved government regulation}

Though problems are clearly widespread within share houses and boarding houses, many international students are unable to avoid this market because they have limited financial means and few other affordable options. Unlike many local students, most international students are unable to live with family or trusted friends or contacts, and lack parental advice to guide their choices. University housing and commercial student accommodation have limited availability and are financially prohibitive for many students; indeed, far fewer students in these types of housing had worked in Australia during their studies. Some international students may know or suspect conditions in a particular share house are poor or risky but accept the room nonetheless, because they do not want to risk losing an affordable bed and a roof over their head and believe they have no affordable alternative. Whatever their financial means, most international students are especially vulnerable to deception and exploitation because they lack knowledge of their rights and standard housing practices.

The fact that problems persist onshore, and in subsequent accommodation, confirms that opportunities for deception and taking financial advantage abound in crowded and expensive Australian urban rental markets, in which the marginal rental sector is under-regulated and lacks systemic government enforcement. Exploitative landlords and property providers are rarely held to account for their conduct, driving cycles of impunity in which the same misconduct is perpetrated against incoming streams of international students.

Lack of accountability stems from several factors. First, international students are generally unable to hold landlords to account for exploitative conduct. As a result of gaps in the law, they commonly lack basic tenancy rights as subtenants in share houses and in boarding houses. For instance, in NSW, international students in share houses who do not have a written agreement with the head tenant are not protected by the state tenancy law, the Residential Tenancies Act 2010 (NSW). International students in share houses commonly do not have a written agreement and therefore lack legal rights. Second, where international students do have legal rights, these are difficult to enforce due to barriers to making claims, and highly limited availability of affordable legal advice and assistance, including limited assistance from education providers. To address these problems, regulatory reforms should be implemented to close legal loopholes and reduce procedural barriers that enable unscrupulous landlords to evade accountability. ${ }^{21}$ State and Commonwealth governments should also substantially increase availability of services to provide international students with tenancy advice and legal assistance, especially for students in smaller education providers like private colleges (in addition to service provision by education providers, discussed below).

Third, compounding students' inability to hold landlords accountable, government efforts to undertake investigations and hold these landlords to account have been limited. Moreover, a lack of coordination between education providers, councils and state government has resulted in missed opportunities for collation of data

20 The authors welcome a forthcoming study by scholars Alan Morris (University of Technology Sydney), Gaby Ramia (University of Sydney) and Shaun Wilson (Macquarie University) involving a further survey of international students across multiple states in Australia that will provide further examination of these issues.

21 See Recommendations, No Place Like Home. For example, state governments should adopt measures to ensure international students can easily reclaim their bond, in order to reduce financial hardship and enable international students to move from unsafe or inadequate accommodation. In NSW, parliament should amend the Residential Tenancies Act 2010 (NSW) and/or government should amend the Residential Tenancies Regulations 2010 (NSW) to provide rights and remedies to the most vulnerable tenants in the marginal rental sector, including international students in share houses who do not have written agreements. The NSW government should also introduce reforms to NSW Civil and Administrative Tribunal processes to increase accessibility for international students. 
to identify repeat offenders for the purpose of government enforcement and warning prospective international students. State government enforcement efforts should be strengthened, and can be made more effective through a well-resourced collaboration between education providers, local councils, NSW Fair Trading, international student groups and tenancy/legal assistance services. This collaboration should facilitate structured information sharing on scams and unscrupulous practices reported by international students, identification of repeat offenders, instigation of investigations by state government. NSW Fair Trading should publish its own findings of unlawful conduct by specific providers as well as findings against providers by relevant tribunals, with links to this list displayed alongside share house advertisements on the main peer-to-peer sharing websites. Local councils with significant international student populations should establish their own centralised investigation system with appropriate referral pathways. ${ }^{22}$

\section{A critical role for the international education sector}

In this context, the international education sector has a critical role to play in empowering international students. International students need targeted information on their rights and red flags to avoid, delivered through the right channels, in the right forms and at the right times. A single consistent package of materials should be developed and systematically delivered pre-departure by education agents, education providers, Commonwealth and state governments and international students' consulates. The content and delivery of this information will be the subject of our forthcoming report. Australian governments (Commonwealth, state and local), education providers, education agents, and consulates must also creatively identify opportunities to provide international students with assistance and information when they are in Australia - both on arrival and throughout their stay.

At the same time, the findings underscore the need for greater assistance from education providers to identify decent share houses and assist international students to evaluate housing offered on these online forums. Overall, among respondents whose first accommodation was in a share house, $98 \%$ organised this alone without assistance from their university or college. Education providers' role must extend beyond information provision to assisting international students to find safe and secure housing more generally - both offshore and onshore. Universities should also establish a dedicated legal service on their campuses that provides tenancy (and employment) advice, staffed by supervised international students.

Providers should also consider facilitating affordable short term accommodation for international students on arrival to provide an opportunity to properly assist them to find decent housing and educate them about their rights and red flags (40\% of those who organised their share house before arrival did so because temporary housing was too expensive, while a third did so because they did not know where to stay while looking for housing). Given the prevalence of serious problems and unfair eviction among international students in share houses, education providers and the NSW government should provide crisis housing and emergency support services to international students to enable students to leave unsafe accommodation and ensure they are not rendered homeless.

\section{Harnessing the leverage of social media and peer-to-peer sharing websites}

Among those whose first accommodation was in a share house, over half organised it through a peer-to-peer sharing website (such as Gumtree, Flatmates.com.au or the Chinese language website/app, Sydney Today) or social media (including Facebook and WeChat). Problems were most commonly experienced among these respondents. Deception, overcharging money upfront and poor living conditions were equally common among students who

22 For further recommendations, see Recommendations, No Place Like Home. For example, the report further recommends that the Commonwealth government establish a Phoenixing Taskforce focused on individuals who provide accommodation and other services to international students (and other temporary migrants) to counter repeat offenders' evasion of liability through liquidation and emergence as a new entity. 
used these channels onshore and those who used them offshore.

These platforms clearly have considerable leverage to curb exploitation and must become partners in efforts to reduce online exploitative practices. They should be encouraged or required through government intervention to do so in two key respects. First, they should display warnings and key information at the moment when it will be most effective - when international students (and others) are searching for housing, whether at home or in Australia. The findings also point to the need for far greater systematic government oversight and investigation of advertisers of housing for international students on these platforms, including identifying deceptive advertising or exploitative practices and swiftly bringing investigative and enforcement efforts to bear. Sharing of information reported by international students to education providers, tenancy and legal service providers and local councils could greatly assist these efforts. Platforms can collaborate with state and local government by swiftly removing or blocking content from advertisers that have engaged in repeat or egregious deceptive or exploitative conduct and assisting government investigation.

\section{Addressing problems in homestays and commercial student accommodation}

Although the greatest number of international students who experienced problems were in share houses and boarding houses, the prevalence of certain specific problems was just as great in some other types of housing that warrant significant attention and reforms. For example, many problems were also experienced by a substantial proportion of international students in homestays, including overcrowding, accommodation that was unsafe or not fit to live in, and intimidation or harassment. One in ten students had their first accommodation in a homestay, with far higher proportions among Chinese students and college students.

Many problems were also experienced among the $7 \%$ of international students whose first accommodation was in commercial student accommodation. This included paying for non-existent accommodation, being told their accommodation was not ready and they had to stay somewhere else (higher than for any other accommodation type), and accommodation that was overcrowded, unsafe or not fit to live in. These problems point to the need for greater government regulation of homestays (including a registration scheme for homestay providers) and stronger oversight mechanisms for commercial student accommodation providers, as detailed in No Place Like Home.

\section{Expanding availability of adequate housing}

The prevalence of problems in share houses underscores the pressing need for universities to increase the availability of affordable accommodation that is available to international students, in collaboration with local and state governments.

In the meantime, education providers, governments (Commonwealth, state and local) and other stakeholders must urgently invest resources in improving regulation and enforcement in relation to share houses and boarding houses, and assisting and empowering international students to navigate these hazardous dark corners of the housing market. 
Figure 21. Problems reported by respondents in either first or subsequent accommodation $(n=2,378)$

I did not get a receipt for money I paid in cash

The accommodation was different to what was described

The landlord made me pay a lot of money upfront

The landlord would not make repairs

The accommodation was overcrowded

The landlord would not give some or all of my bond back

The accommodation was unsafe or not fit to live in

I was intimidated or harassed in other ways by my landlord or other tenants

The landlord suddenly increased the rent in the middle of the rental period

I paid for accommodation that did not exist

I was told the accommodation was not ready and I had to stay somewhere else

The landlord moved extra people into my accommodation and I had not agreed to this

I was unfairly evicted

I was on the lease and became responsible for other subtenants

The landlord did not give me their correct contact information

Other

I was sexually harassed by my landlord or other tenants

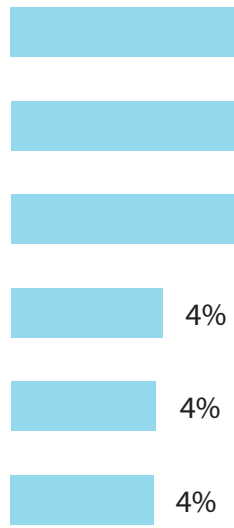




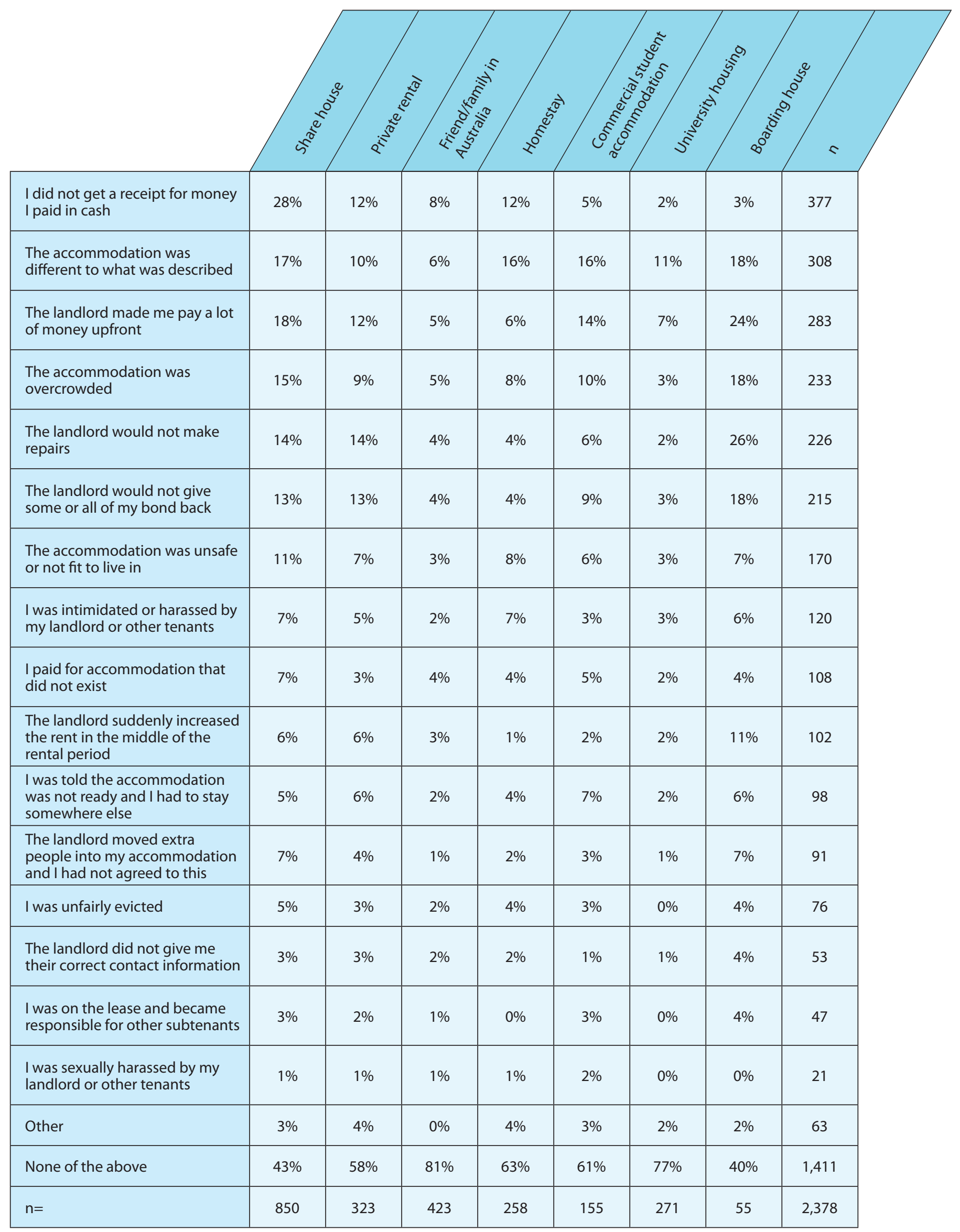




\begin{tabular}{|c|c|c|c|c|c|c|c|c|c|c|c|c|c|c|c|c|c|}
\hline $\begin{array}{l}\text { I did not get a receipt for money } \\
\text { I paid in cash }\end{array}$ & $3 \%$ & $12 \%$ & $20 \%$ & $6 \%$ & $17 \%$ & $5 \%$ & $0 \%$ & $3 \%$ & $7 \%$ & $4 \%$ & $2 \%$ & $8 \%$ & $0 \%$ & & $5 \%$ & 13 & $3 \%$ \\
\hline $\begin{array}{l}\text { The accommodation was } \\
\text { different to what was described }\end{array}$ & $17 \%$ & $20 \%$ & $19 \%$ & $20 \%$ & $21 \%$ & $14 \%$ & $14 \%$ & $21 \%$ & $18 \%$ & $11 \%$ & $20 \%$ & $17 \%$ & $14^{c}$ & & $10 \%$ & 20 & \\
\hline $\begin{array}{l}\text { The landlord made me pay a lot } \\
\text { of money upfront }\end{array}$ & $6 \%$ & $8 \%$ & $8 \%$ & $8 \%$ & $11 \%$ & $4 \%$ & $5 \%$ & $10 \%$ & $5 \%$ & $7 \%$ & $3 \%$ & $2 \%$ & $2 \%$ & & $8 \%$ & 89 & \\
\hline $\begin{array}{l}\text { The accommodation was } \\
\text { overcrowded }\end{array}$ & $15 \%$ & $23 \%$ & $21 \%$ & $26 \%$ & $13 \%$ & $8 \%$ & $26 \%$ & $20 \%$ & $13 \%$ & $11 \%$ & $10 \%$ & $13 \%$ & $8 \%$ & & $18 \%$ & 13 & $\%$ \\
\hline $\begin{array}{l}\text { The landlord would not make } \\
\text { repairs }\end{array}$ & $23 \%$ & $22 \%$ & $20 \%$ & $23 \%$ & $26 \%$ & $17 \%$ & $40 \%$ & $19 \%$ & $17 \%$ & $14 \%$ & $7 \%$ & $29 \%$ & $8 \%$ & & $18 \%$ & 33 & $\%$ \\
\hline $\begin{array}{l}\text { The landlord would not give } \\
\text { some or all of my bond back }\end{array}$ & $18 \%$ & $15 \%$ & $19 \%$ & $10 \%$ & $12 \%$ & $8 \%$ & $18 \%$ & $10 \%$ & $12 \%$ & $11 \%$ & $7 \%$ & $10 \%$ & $4 \%$ & & $10 \%$ & 13 & \\
\hline $\begin{array}{l}\text { The accommodation was unsafe } \\
\text { or not fit to live in }\end{array}$ & $2 \%$ & $3 \%$ & $2 \%$ & $0 \%$ & $2 \%$ & $1 \%$ & $0 \%$ & $3 \%$ & $2 \%$ & $4 \%$ & $2 \%$ & $2 \%$ & $0 \%$ & & $3 \%$ & 39 & \\
\hline $\begin{array}{l}\text { I was intimidated or harassed } \\
\text { in other ways by my landlord or } \\
\text { other tenants }\end{array}$ & $7 \%$ & $10 \%$ & $8 \%$ & $14 \%$ & $8 \%$ & $4 \%$ & $5 \%$ & $10 \%$ & $8 \%$ & $13 \%$ & $5 \%$ & $10 \%$ & $6 \%$ & & $3 \%$ & 13 & \\
\hline $\begin{array}{l}\text { I paid for accommodation that } \\
\text { did not exist }\end{array}$ & $11 \%$ & $12 \%$ & $8 \%$ & $15 \%$ & $14 \%$ & $10 \%$ & $6 \%$ & $12 \%$ & $7 \%$ & $16 \%$ & $19 \%$ & $13 \%$ & $4 \%$ & & $3 \%$ & 13 & \\
\hline $\begin{array}{l}\text { The landlord suddenly increased } \\
\text { the rent in the middle of the } \\
\text { rental period }\end{array}$ & $16 \%$ & $17 \%$ & $17 \%$ & $19 \%$ & $12 \%$ & $7 \%$ & $15 \%$ & $9 \%$ & $15 \%$ & $16 \%$ & $12 \%$ & $10 \%$ & $8 \%$ & & $8 \%$ & 28 & \\
\hline $\begin{array}{l}\text { I was told the accommodation } \\
\text { was not ready and I had to stay } \\
\text { somewhere else }\end{array}$ & $5 \%$ & $6 \%$ & $8 \%$ & $11 \%$ & $7 \%$ & $6 \%$ & $11 \%$ & $4 \%$ & $8 \%$ & $4 \%$ & $2 \%$ & $6 \%$ & $4 \%$ & & $3 \%$ & 15 & \\
\hline $\begin{array}{l}\text { The landlord moved extra } \\
\text { people into my accommodation } \\
\text { and I had not agreed to this }\end{array}$ & $21 \%$ & $16 \%$ & $15 \%$ & $18 \%$ & $18 \%$ & $12 \%$ & $14 \%$ & $14 \%$ & $7 \%$ & $7 \%$ & $7 \%$ & $13 \%$ & $6 \%$ & & $5 \%$ & 18 & \\
\hline I was unfairly evicted & $8 \%$ & $9 \%$ & $8 \%$ & $3 \%$ & $5 \%$ & $5 \%$ & $5 \%$ & $5 \%$ & $15 \%$ & $7 \%$ & $3 \%$ & $4 \%$ & $2 \%$ & & $8 \%$ & 10 & \\
\hline $\begin{array}{l}\text { The landlord did not give me } \\
\text { their correct contact information }\end{array}$ & $7 \%$ & $6 \%$ & $9 \%$ & $2 \%$ & $6 \%$ & $7 \%$ & $8 \%$ & $4 \%$ & $8 \%$ & $5 \%$ & $3 \%$ & $6 \%$ & $0 \%$ & & $8 \%$ & 39 & \\
\hline $\begin{array}{l}\text { I was on the lease and became } \\
\text { responsible for other subtenants }\end{array}$ & $4 \%$ & $5 \%$ & $4 \%$ & $3 \%$ & $4 \%$ & $1 \%$ & $6 \%$ & $5 \%$ & $10 \%$ & $4 \%$ & $0 \%$ & $0 \%$ & $2 \%$ & & $0 \%$ & 59 & \\
\hline $\begin{array}{l}\text { I was sexually harassed by my } \\
\text { landlord or other tenants }\end{array}$ & $5 \%$ & $3 \%$ & $6 \%$ & $4 \%$ & $5 \%$ & $1 \%$ & $4 \%$ & $3 \%$ & $8 \%$ & $5 \%$ & $2 \%$ & $2 \%$ & $2 \%$ & & $5 \%$ & 59 & \\
\hline Other & $3 \%$ & $3 \%$ & $4 \%$ & $5 \%$ & $1 \%$ & $4 \%$ & $3 \%$ & $5 \%$ & $5 \%$ & $7 \%$ & $3 \%$ & $0 \%$ & 09 & & $3 \%$ & 10 & $\%$ \\
\hline None of the above & $45 \%$ & $50 \%$ & $48 \%$ & $41 \%$ & $48 \%$ & $59 \%$ & $38 \%$ & $47 \%$ & $3 \%$ & $66 \%$ & $58 \%$ & $52 \%$ & 72 & & $58 \%$ & 45 & $\%$ \\
\hline $\mathrm{n}=$ & 596 & 314 & 192 & 95 & 84 & 98 & 80 & 81 & 60 & 56 & 59 & 48 & $5 c$ & & 40 & 4 & 0 \\
\hline
\end{tabular}


